Florida International University FIU Digital Commons

FIU Electronic Theses and Dissertations

University Graduate School

3-27-2013

\title{
Vocabulary Comprehension in Children with Autism
}

Melissa A. Pierro

Florida International University, mpierro20@aol.com

DOI: $10.25148 /$ etd.FI13042323

Follow this and additional works at: https://digitalcommons.fiu.edu/etd

Part of the Speech and Hearing Science Commons, and the Speech Pathology and Audiology Commons

\section{Recommended Citation}

Pierro, Melissa A., "Vocabulary Comprehension in Children with Autism" (2013). FIU Electronic Theses and Dissertations. 862. https://digitalcommons.fiu.edu/etd/862

This work is brought to you for free and open access by the University Graduate School at FIU Digital Commons. It has been accepted for inclusion in FIU Electronic Theses and Dissertations by an authorized administrator of FIU Digital Commons. For more information, please contact dcc@fiu.edu. 


\section{FLORIDA INTERNATIONAL UNIVERSITY}

Miami, Florida

VOCABULARY COMPREHENSION IN CHILDREN WITH AUTISM

A thesis submitted in partial fulfillment of the

requirements for the degree of

MASTER OF SCIENCE

in

SPEECH LANGUAGE PATHOLOGY

by

Melissa Pierro

2013 
To: $\quad$ Dean Ora Lea Strickland

College of Nursing and Health Sciences

This thesis, written by Melissa Pierro, and entitled Vocabulary Comprehension in Children with Autism, having been approved in respect to style and intellectual content, is referred to you for judgment.

We have read this thesis and recommend that it be approved.

Monica Hough

Eliane Ramos

Ana Gouvea, Major Professor

Date of Defense: March 27, 2013

The thesis of Melissa Ann Pierro is approved.

Dean Ora Lea Strickland College of Nursing and Health Sciences

Dean Lakshmi N. Reddi University Graduate School

Florida International University, 2013 
(C) Copyright 2013 by Melissa Pierro

All rights reserved. 


\section{DEDICATION}

I would like to dedicate this thesis to all of the children with autism I have worked with throughout the years who have each inspired and touched my heart in more ways than one. You will never cease to amaze me. 


\section{ACKNOWLEDGMENTS}

I wish to thank the members of my committee for their support and patience. Their compassionate and knowledgeable direction has been most appreciated. I would also like to thank my Professor, Dr. Eliane Ramos, for her insight and development of this most interesting research study she so graciously let me be a part of. I would also like to especially thank my major Professor, Dr. Ana Gouvea, for her continued guidance, knowledge, and patience throughout this process. Finally, I would like to thank Florida International University's College of Nursing and Health Sciences, especially the faculty of the Communication Sciences and Disorders Department for providing me with the outstanding curriculum and hands-on experience to become a confident Speech Language Pathologist and researcher in the field. 


\title{
ABSTRACT OF THE THESIS \\ VOCABULARY COMPREHENSION IN CHILDREN WITH ATUTISM
}

\author{
by
}

Melissa Pierro

Florida International University, 2013

Miami, Florida

\section{Professor Ana Gouvea, Major Professor}

An open question in autism research is how to assess language abilities in this population. We investigated language development in monolingual and bilingual children with varying degrees of autism, ages 3 to 9, with the aim of better understanding vocabulary comprehension. Two different methodologies were used: the Receptive OneWord Picture Vocabulary Test (ROWPVT) and eye-tracker technique.

We examined whether the eye-tracker could help in the assessment of these children because it does not require the child to point during the test. Four typically developing control children, 14 monolingual English children with moderate/mild autism, and 4 children ( 2 monolingual English, 2 bilingual Spanish/English) with severe autism were tested and the results of the ROWPVT test were compared to the eye-tracker results. Interestingly, bilingual children with severe autism had better results using eye-tracker than the traditional ROWPVT test. These results suggest that these children know more vocabulary than traditional test measures indicate. 
CHAPTER PAGE

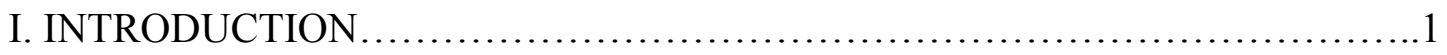

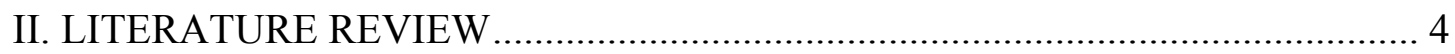

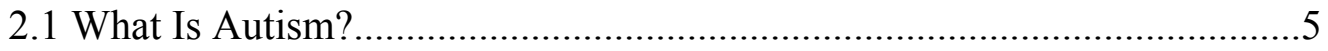

2.2 Overview of Typical Language Development ........................................... 9

2.2.1 Vocabulary Development .......................................................... 17

2.3 Overview of Language Development in Bilingual Children................23

2.3.1 Vocabulary Development in Bilingual Children ................................... 28

2.4 Language Development in Children with Autism ..................................... 31

2.5 Language Development of Bilingual Children with Autism................34

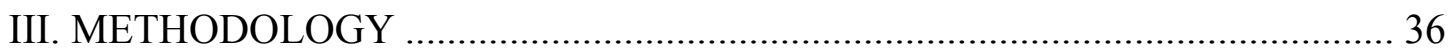

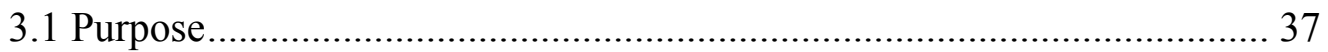

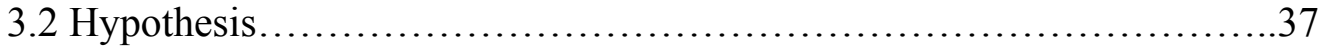

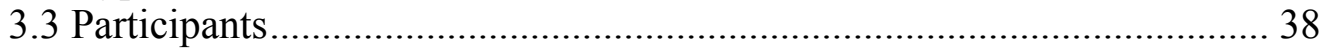

3.4 Stimuli/ Apparatus .............................................................................. 40

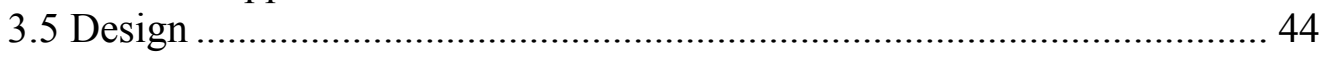

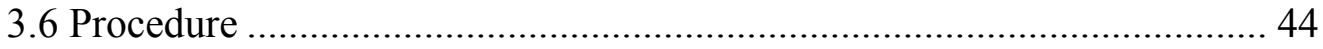

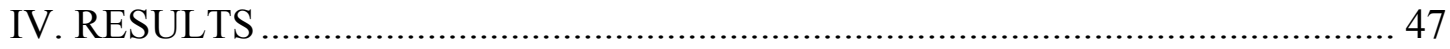

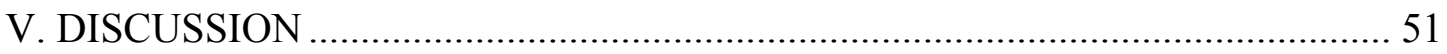

5.1 Components of Investigation ............................................................... 52

5.2 General Discussion ........................................................................... 53

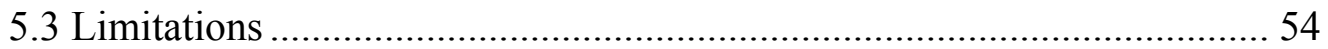

5.4 Implications for Future Research ......................................................... 55

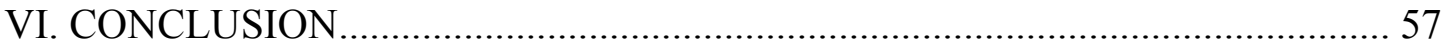

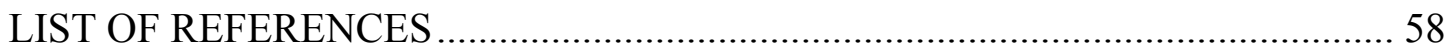

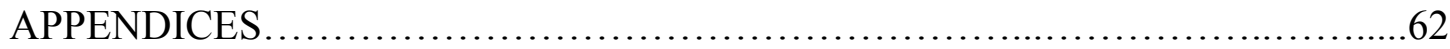





\section{CHAPTER I. INTRODUCTION}

This thesis investigated language comprehension abilities in children with varying degrees of autism using a standardized test and the eye-tracker technique. Language abilities in children with autism are generally assessed using vocabulary tests like the Receptive One-Word Picture Vocabulary Test (ROWPVT) (Benson, 2002). A test such as this requires interaction between the Speech Language Pathologist and the client as the child is expected to point to pictures. Given the social interaction problems characteristic of children with autism and in the Autism Specturm Disorders (ASD) population, the language capacities of these children may not be completely assessed because they are required to interact and point to pictures. Alternatively, eye-tracking captures and records children's eye movements and may help in the assessment of language abilities in children with autism because it does not require any interaction or pointing. Thus, we examined whether eye-tracker may provide a more accurate measure of these children's language comprehension abilities (Blakemore, 2009).

ASD are a constellation of psychiatric conditions (Lord, 1995). Characteristics include difficulties in socialization, communication, and behavior. Although ASD appear to be rooted in very early brain development, the most obvious signs of autism and symptoms of autism tend to emerge between 2 and 3 years of age (Koope, Eaves, and Ho, 2001). According to the U.S. Center for Disease Control and Prevention (CDC) 1 in 88 American children ( 1 in 54 boys and 1 in 252 girls) are on the autism spectrum, a ten-fold increase in prevalence in the last 40 years. Moreover, autism statistics show that prevalence rates have increased 10 to 17 percent annually in recent years, affecting over 2 million individuals in the U.S. ASD is a lifelong disability in more than $95 \%$ of the 
people diagnosed with the syndrome. It affects a variety of social, affective, and cognitive skills and has a prominent influence on communication (Shipley \& McAfee, 2009).

From early in development, children with ASD exhibit differences in intentional communication (Shipley \& McAfee, 2009). Typically, they do not communicate to share joint focus with another individual, but solely to express wants and needs. In terms of language development, children with autism tend to be delayed in typical language development milestones, such as babbling and speaking (Charman, Drew, and Baird, 2003). Children with autism may also present difficulties in combining words in meaningful sentences, may speak only single words or repeat the same phrase over and over. They may also go through a stage in which they repeat what they hear, known as echolalia. These children begin speaking late and develop speech at a significantly slower pace than normal developing children (Charman, Swettenham, and Baron-Cohen, 1997). In fact, some children with ASD do not develop speech at all; however, the percentage of this subgroup is declining due to early identification and intervention (Filipek, 2000). When speaking, children with ASD often show sparse verbal expression and exhibit a lack of spontaneity. They often have trouble adapting what they say to the needs and status of the listener, distinguishing given from new information, following politeness rules, making relevant comments, maintaining topics outside their own obsessive interests, and partaking in appropriate conversational turn taking with listeners (Scott, 2012). Children with ASD may use nonreciprocal speech, which is classified as nondirected or non-responsive to others (Shipley \& McAfee, 2009). Sometimes it may seem as if these children are in their own little worlds. 
A topic that is becoming increasingly important in the autism language development literature is whether children with ASD have receptive language skills that exceed their expressive capabilities. In other words, do children with autism know more words and language than they can expressively communicate?

The aim of this thesis is to study the receptive language abilities of children with ASD by examining their vocabulary comprehension using a paper and pencil standardized test, the ROWPVT- Receptive One-Word Picture Vocabulary Test, and the eye-tracker technique. Thus, this thesis examined the receptive vocabulary abilities of monolingual and bilingual (Spanish/ English) children with ASD, ages 3 to 9 years old, through the use of elicitation by pointing (ROWPVT) as well as eye gaze as recorded by the eye tracker device.

Children with ASD are often diagnosed as having language disorders due to their lack of expressive language capabilities. They are often classified as quiet or reserved relative to communicating. However, this does not mean that they are not able to develop language representations or that they do not have the ability to understand and process language (Stone, Lee, Ashford, Brissie, Hepburn, Coonrod, and Weiss, 1998). By examining receptive language skills independent of required elicitation, the results of this thesis contribute to a better understanding of these children's language capacities. Thus, this research is particularly relevant for the areas of Health Sciences and Communication Disorders and its outcome is potentially significant for the assessment of vocabulary knowledge in children with ASD. 
CHAPTER II. LITERATURE REVIEW 


\subsection{What is Autism?}

Autism spectrum disorder (ASD) or Pervasive developmental disorder (PDD) is a disorder characterized by impairment in communication and social skills as well as stereotyped and restricted behavioral patterns (Shipley \& McAfee, 2009). It has three primary characteristics. First and secondly, it is characterized by a qualitative impairment in communication, accompanied by a qualitative impairment in establishing social relationships. Thirdly, a person with ASD most likely will present restricted, repetitive, and stereotyped patterns of behavior, interests, or activities (American Psychiatric Association, 2000). The disorder was first described in 1943 by child psychiatrist Dr. Leo Kanner. From then on, the definition of autism evolved and broadened across time. The autism spectrum we understand today was defined in the 1980's (Benson, 2002). However, as it has only been recognized recently as a disorder, there is still much to be learned about its cause and appropriate interventions (Shipley \& McAfee, 2009). Today, autism spectrum is composed of five disorders, which include: autism, Asperger's syndrome, childhood disintegrative disorder, Rett syndrome, and pervasive developmental disorder- not otherwise specified (PPD-NOS) (Scott, 2012). The primary characteristics of each as defined in the DSM-IV are explained in the following paragraphs. In all cases, the incidence of ASD is higher among boys than girls with a 4 to 1 ratio (Shipley \& McAfee, 2009).

Autism is a communication impairment characterized by restricted, repetitive, and stereotyped patterns of behavior, interests, and activities (Charman, Swettenham, and Baron-Cohen, 1997). Delayed or abnormal functioning in one of the following areas will 
likely be present prior to the age of three years. They are social interaction, language used in social communication, and symbolic or imaginative play (Shipley \& McAfee, 2009).

Asperger's syndrome, sometimes called "high-functioning autism," shares many characteristics with the autism disorder previously described. It is classified as an impairment in social interaction (Filipek, 2000). Once again, individuals with Asperger's syndrome will display restricted, repetitive and stereotyped patterns of behavior, interests, and activities. They will most likely exhibit normal language and cognitive development as well as normal self-help and adaptive behaviors (Shipley \& McAfee, 2009).

Childhood Disintegrative Disorder is a rare disorder characterized by at least two years of normal development across all domains including; receptive and expressive communication, social relationships, play, adaptive behavior, and motor skills, followed by a significant loss of previously acquired skills, with residual deficits fulfilling the diagnostic criteria for ASD (Shipley \& McAfee, 2009).

Rett Syndrome, another rare disorder, is seen when there is normal development until between 5 months and 48 months of age (Koope, Eaves, and Ho, 2001). This onset of a progressive degeneration that begins between the ages of 5 months and 48 months is evidenced by a deceleration in growth of head circumference, hand movements which progress to nonfunctional hand-wringing, and poor motor coordination for walking (Lord, 1995). A significant speech and language disorder with a pronounced oral-motor component will also be present. Rett Syndrome is almost exclusively a female disorder as it has autosomal dominant inheritance (Shipley \& McAfee, 2009). 
Pervasive Developmental Disorder - Not Otherwise Specified (PDD-NOS) has similar characteristics of the autism spectrum disorder however, does not meet the criteria of the other four PDDs (American Psychiatric Association, 1994).

Due to the significant communicative deficits characteristic of ASD, speechlanguage pathologists are important members of the interdisciplinary team responsible for its assessment and diagnosis (Benson, 2000). They work in conjunction with pediatricians, neurologists, psychiatrists, psychologists, occupational therapists, social workers, nurses, teachers, and audiologists. It is important for speech language pathologists to be knowledgeable and experienced in differentiating ASD from other conditions (Shipley \& McAfee, 2009). ASD is currently diagnosed in the preschool years or later, although there is an increasing base of knowledge that is encouraging earlier diagnosis. It is important for members of the medical community to diagnose ASD as early as possible so that appropriate interventions can begin (Charman, Drew, and Baird, 2003). Current research demonstrates that earlier diagnoses before children are three years of age are essentially stable, as children do not outgrow the disorder (Charman. Swettenham, and Baron-Cohen, 1997).

Distinctions between the five disorders of the autism spectrum previously described are not clearly defined until a child is older. However, there are a variety of early indicators that apply to all of them comprehensively. Many of the early signs of ASD have more to do with what a child does not do, rather than what a child does. Young children with autism are less likely to respond to social bids, smile responsively, reciprocate affection, establish eye contact during interactions, imitate the actions of others (e.g., wave good-bye), repeat actions that produce attention or laughter, show 
interest in other children, use gestures to communicate, understand language or gestures, engage in a broad repertoire of functional play activities, create simple play schemes or sequences with toys, and engage in imaginative play (Shipley \& McAfee, 2009). Young children with autism may demonstrate some or all of the following; the ability to engage in repetitive play activities, demonstrate repetitive motor behaviors, respond inconsistently to sounds, and show unusual visual interests (e.g., spinning or studying objects) (Benson, 2002; Koope, Eaves, \& Ho, 2001; Stone, Lee, Ashford, et al., 1998). While the previous behaviors may or may not be early signs of autism spectrum disorders, the presence of the following behaviors are absolute indicators of a need for further evaluation. These include no babbling or gesturing by 12 months, no single words by 16 months, no spontaneous two-word phrases by 24 months, and a significant loss of any language or social skills at any age (Filipek, 2000; Koope et. al., 2001).

In the next sections, an overview of how children typically develop language is presented. Vocabulary development is a primary focus as the topic of this thesis is vocabulary comprehension in children with ASD. Since monolingual and bilingual Spanish/English children with ASD were tested, a discussion of bilingual vocabulary and language development is also presented. Finally, language development in children with autism is discussed. 


\subsection{Overview of Typical Language Development}

Language development begins early in an infant's life. In general, there is a developmental sequence of language development stages observed in children. Below is an outline of typical speech and language development for age appropriateness at different time intervals. The information was compiled from a variety of sources including, Apel and Masterson (2001); Gard, Gilman, and Gorman (1993); Hegde (2001); and Nicolosi, Harryman, and Kresheck (2004). However, it is important to keep in mind that all children develop at different rates, so these age approximations should not be strictly applied.

0-6 Months:

- Frequently coos, gurgles, and makes pleasure sounds

- Uses a different cry to express different needs

- Smiles when spoken to

- Recognizes voices

- Localizes to sound

- Listens to speech

- Uses the phonemes $/ \mathrm{b} /, / \mathrm{p} /$, and $/ \mathrm{m} /$ in babbling

- Uses sounds or gestures to indicate wants

- Responds to "no" and changes in tone of voice

7-12 Months:

- Understands "no" and "hot"

- Responds to simple requests 
- Understands and responds to own name

- Recognizes words for common items (ex. Cup, shoe, juice)

- Babbles using long and short groups of sounds

- Uses a large variety of sounds in babbling

- Imitates some adult speech sounds and intonation patterns

- Uses speech sounds rather than only crying to get attention

- Listens when spoken to

- Uses sound approximations

- Begins to change babbling to jargon

- Uses speech intentionally for the first time

- Uses nouns almost exclusively

- Has an expressive vocabulary of 1 to 3 words

- Uses characteristic gestures or vocalizations to express wants

13-18 Months:

- Imitates individual words

- Uses adult-like intonation patterns

- Uses echolalia and jargon

- Omits some initial consonants and almost all final consonants

- Produces mostly unintelligible speech

- Follows simple commands

- Receptively identifies one to three body parts

- Has an expressive vocabulary of 3 to 20 or more words (mostly nouns) 
- Combines gestures and vocalization

- Makes requests for more of desired items

19-24 Months:

- Uses words more frequently than jargon

- Has an expressive vocabulary of 50-100 or more words

- Has a receptive vocabulary of 300 or more words

- Starts to combine nouns with verbs and nouns with adjectives

- Begins to use pronouns

- Maintains unstable voice control

- Uses appropriate intonation for questions

- Is approximately $25-50 \%$ intelligible to strangers

- Asks and answers "what's that?" questions

- Enjoys listening to stories

- Knows five body parts

- Accurately names a few familiar objects

- Understands basic categories (ex. Toys, food)

- Points to pictures in a book when named

2-3 Years:

- Speech is $50-75 \%$ intelligible

- Understands "one" and "all"

- Verbalizes toilet needs (before, during, or after act)

- Requests items by name 
- Identifies several body parts

- Follows 2-part commands

- Asks 1 to 2 word questions

- Uses 2 to 4 word phrases

- Uses words that are general in context

- Continues use of echolalia when difficulties in speech are encountered

- Has a receptive vocabulary of 500-900 or more words

- Has an expressive vocabulary of 500-250 or more words (rapid growth during this period)

- Exhibits multiple grammatical errors

- Understands most things said to him or her

- Frequently exhibits repetitions- especially starters, "I," and first syllables

- Speaks with a loud voice

- Increases range of pitch

- Uses vowels correctly

- Consistently uses initial consonants (although some are misarticulated)

- Frequently omits medial consonants

- Frequently omits or substitutes final consonants

- Uses auxiliary "is" including the contracted form

- Uses some regular past tense verbs, possessive morphemes, pronouns, and imperatives

- Maintains topic over several conversational turns 


\section{3-4 Years:}

- Understands object functions

- Understands opposites (stop-go, in-on, big-little)

- Follows 2 and 3 part commands

- Produces simple verbal analogies

- Uses language to express emotion

- Uses 4 to 5 words in a sentence

- Repeats 6- to 13-syllable sentences accurately

- May continue to use echolalia

- Uses nouns and verbs most frequently

- Is conscious of past and future

- Has a 1,200-2,000 or more word receptive vocabulary

- Has a 800-1,500 or more word expressive vocabulary

- May repeat self often, exhibiting blocks, disturbed breathing, and facial grimaces during speech

- Increases speech rate

- Speech is approximately $80 \%$ intelligible

- Appropriately uses "is," "are" and "am" in sentences

- Tells 2 events in chronological order

- Engages in long conversations

- Sentence grammar improves, although some errors still persist

- Uses some contractions, irregular plurals, future tense verbs, and conjunctions 
- Consistently uses regular plurals, possessives and simple past tense verbs

- Uses an increasing number of compound or complex sentences

\section{4-5 Years:}

- Imitatively counts to five

- Continues understanding of spatial concepts

- Has a receptive vocabulary of 10,000 or more words

- Counts to 10 by rote

- Listens to short, simple stories and can answer questions about them

- Answers questions about function

- Uses adult-like grammar most of the time

- Grammatical errors primarily in irregular forms, reflexive pronouns, adverbial suffixes, and comparable/ superlative inflections

- Has an expressive vocabulary of 900-2,000 or more words

- Uses sentences of 4 to 8 words

- Answers complex 2-part questions

- Asks for word definitions

- Speaks at a rate of approximately 186 words per minute

- Reduces total number of repetitions

- Significantly reduces number of persistent sound omissions and substitutions

- Frequently omits medial consonants

- Speech is usually intelligible to strangers even though some articulation errors may persist 
- Accurately tells about experiences at school, at friends' homes, ect.

5-6 Years:

- Follows instructions given to a group

- Asks "how" questions

- Uses past tense and future tense appropriately

- Uses conjunctions

- Has a receptive vocabulary of approximately 13,000 words

- Sequentially names days of the week

- Counts to 30 by rote

- Continues to drastically increase vocabulary

- Uses sentence length of 4 to 6 words

- Reverses sounds occasionally

- Exchanges information and asks questions

- Uses sentences with details

- Accurately relays a story

- Sings entire songs and recites nursery rhymes

- Communicates easily with adults and other children

- Uses appropriate grammar in most cases

6-7 Years:

- Understands left and right

- Uses increasingly more complex descriptions

- Engages in conversations 
- Has a receptive vocabulary of approximately 20,000 words

- Uses a sentence length of approximately 6 words

- Understands most concepts of time

- Counts to 100 by rote

- Uses most morphological markers appropriately

- Uses passive voice appropriately

In the next section vocabulary development in typically developing children is discussed. 


\subsubsection{Vocabulary Development}

This study focuses mainly on examining children's semantic knowledge, particularly vocabulary development. Semantics is the study of language meaning, which can be expressed verbally, vocally, and gesturally (Shipley \& McAfee, 2009). Meaning is complex and heavily influenced by content. Word definitions, syntactic or grammatical structures, pragmatic behaviors and suprasegmental aspects of language intertwine to give language meaning (Shipley \& McAfee, 2009).

In the very beginning of a child's life, word learning is slow and new words show up at the rate of approximately one a week. This process speeds up however; at about the time children reach the fifty-word milestone, which is normally seen at age eighteen months (O'Grady, 2005). This is often the beginning of a "vocabulary spurt" during which children learn one or two new words a day (Clark, 1993). In some children, the spurt doesn't take place until the vocabulary contains over one hundred words, and approximately one-third of all children acquire words at a steady pace or in a series of small bursts with no sudden leap forward (Goldfield \& Reznick, 1990). In fact, it seems that children are able to learn a new word after hearing it used only once or twice. This rapid learning is sometimes called fast mapping (O’Grady, 2005). At later ages, word learning becomes even faster, averaging about ten new words a day between age two and six (Bloom, 2000). As a matter of fact, by age six, children have a vocabulary of about 14,000 words, and they go on to learn as many as twenty new words per day over the next several years (Bloom \& Markson, 1998).

There appear to be two different styles in which children learn language: the analytic style and the gestalt style (Peters, 1977). The analytic style focuses on breaking 
speech into its smallest component parts from the very beginning. Children who use this style produce short, clearly articulated, one-word utterances in the early stages of language learning. They have a preference to name people and objects, and use simple words to describe how they feel and what they want (O'Grady, 2005). On the other hand, some children take a different approach. These children memorize and produce relatively large chunks of often poorly articulated speech that correspond to entire sequences of words in the adult language (O'Grady, 2005). This is referred to as the gestalt style of language learning. It is best to think of the analytic-gestalt contrast as a continuum. This is because no child employs a completely analytic strategy or a purely gestalt style, but they exhibit tendencies in one direction or another to learn new words (O'Grady, 2005).

Every language's vocabulary is a work in progress. Words fall out of use and new words are introduced on a daily basis. Children are aware of this constant change and often create their own words (O'Grady, 2005). In fact, children start using a process called conversion, in which they take a word that already exists and start to use it in a new way, by the time they are two years old (O'Grady, 2005). In this sense, children are extraordinarily good at finding meanings for words and words for meaning (Clark, 1993). Children have a very reasonable word-learning priority- they want to know the names for the people and things they have been seeing since they were born (O'Grady, 2005). Because of this, their first words tend to have meanings that are very close to home and consist primarily of nouns (Goldfield, 2000). All children tend to have more nouns than any other type of word in their early vocabulary, but the strength of the preference can vary from child to child (O'Grady, 2005). This distinction is made by classifying children as "noun-lovers" or "noun-leavers." Children whose early vocabulary consists almost 
exclusively of nouns are sometimes called "referential or noun-lovers" because so many of their early words are used to refer to people and objects (O'Grady, 2005). On the other hand, children who are less favorable to nouns are sometimes called "expressive or nounleavers" since they tend to concentrate more on words and phrases that express relations and activities (O’Grady, 2005). This second group of children are also more likely to adopt a gestalt style of learning, so many of their first utterances are large chunks of speech (Clark, 1993).

Often, assessing semantic knowledge can be difficult due to its inherent complexity and a lack of normative standards among children. Below is an account of semantic milestones noted in early communication development. However, in general, when assessing semantic knowledge it is important to look for variety. The more mature the speaker, the greater the range of words and type of words the speaker should exhibit in their vocabulary. Children with semantic language disorders usually demonstrate limited vocabularies and difficulty integrating semantic information with other aspects of language, especially grammar (Shipley \& McAfee, 2009). The following information on semantic language development from birth to 9 years old, for purposes of this study, was taken from Chapman (2000), Miller (1981), and Weiss, Gordon, and Lillywhite (1987). Similar to the information previously presented on typical language development, each child develops differently according to a multitude of factors. Therefore, this information should not be taken as a literal guide for each chronological milestone.

0 to 8 Months:

- No significant semantic development at this point. Caregivers are responsible for attributing intent to their child's actions. 
8 to 12 Months:

- Understanding of 3 to 50 words.

- First words used for names of familiar people and objects.

- Communicative games and routines to talk about appearance, disappearance, and recurrence.

12 to 18 Months:

- Average expressive vocabulary size: 50 to 100 words at 18 months.

- Semantic roles expressed in one word speech include: agent, action, object, location, possession, rejection, disappearance, nonexistence and denial.

- Words are understood outside of routine games; still need contextual support for lexical comprehension.

18 to 24 Months:

- Average expressive vocabulary size: 200 to 300 words at 24 months.

- Understands single words for objects out of sight.

- Understands two-word relations similar to those expressed.

- Prevalent relations expressed: agent-action, agent-object, action-object, actionlocation, entity-location, possessor-possession, demonstrative-entity, and attribute-entity.

24 to 30 Months:

- Understanding and use of questions about object (what?), people (who?), basic events (what (x) doing? Where (x) going?).

30 to 36 Months: 
- Use and understanding of "why" questions.

- Understanding and use of basic spatial terms (in, on, under, etc.).

36 to 42 Months:

- Semantic relations between adjacent and conjoined sentences include; additive, temporal, causal, and contrastive.

- Understanding of basic color words.

- Use and understanding of basic kinship terms.

42- 48 Months:

- Use and understanding of "when" and "how" questions.

- Understanding of words for basic shapes (circle, square, triangle).

- Use and understanding of basic size vocabulary (big, small).

- Use of conjunctions "and, because" to conjoin sentences.

48- 60 Months:

- Knowledge of letter names and sounds emerges.

- Knowledge of numbers and counting emerges.

- Use of conjunctions, "when, so, because and if".

5 to 7 Years:

- Reorganization of lexical knowledge from syntagmatic (episodic) to paradigmatic (semantic) networks.

- Average expressive vocabulary size is 3,000 to 5,000 words.

7 to 9 Years: 
- School and reading experience introduce new words not encountered in conversation.

- Pronouns used anaphorically to refer to nouns previously named.

- Word definitions include synonyms and categories.

- Some words understood to have multiple meanings.

- Capacity for production of figurative language increases.

In the last two sections some characteristics of typical language development in monolingual children were addressed. In this thesis' experiment, monolingual and bilingual (Spanish/English) children with ASD are tested. Thus, in the next section an overview of bilingual vocabulary and language development is provided with the aim of discussing whether bilingual children go through the same developmental stages as monolingual children. In other words, whether bilingual language development is different from monolingual development is addressed. 


\subsection{Overview Of Language Development in Bilingual Children}

Paradis, Genesee, and Crago (2010) identify two types of bilingual children: those who are simultaneous language learners and those who are second language learners. Simultaneous bilingual children are those who acquire two languages from birth or at least before the age of 3 . The bilingual children in our experiment are simultaneous bilingual children. These children acquired both English and Spanish at approximately the same time. Second language learners are children who are exposed to another language after the age of 3 . This age is used as a cut-off because around this age, children have already acquired the main grammatical properties of the first language, or in other words, these children have already established one language system. Because the children tested in our experiment are simultaneous bilinguals, simultaneous bilingual acquisition is discussed. The literature on simultaneous bilingual development shows that simultaneous bilingual children go through the same stages as monolingual children at around the same age. Thus, bilingual children are not behind monolingual children.

Historically, bilingualism has been considered an intellectual disadvantage to children learning two languages early in their development. Differences between bilingual and monolingual language development were viewed negatively. Often bilingual children were considered typically developing only if they appeared to be like monolingual children and they were considered to have disabilities if they showed any differences (Paradis, Genesee, \& Crago, 2010). However, recent research has proven that this is not the case.

The question of whether bilingual children are different from monolingual children has inspired hypotheses on how bilingual children develop language. In one 
view, children do not acquire language bilingually at first, but rather go through a stage in which the two input languages are treated as if they were part of a single language system. This is known as the Unitary Language System Hypothesis (Volterra \& Taeschner, 1978). The first stage is composed of a single language system that combines the words and the grammatical rules from their dual language input. In the second stage, words are differentiated in two vocabularies/ lexicons, but the system of grammatical rules remains the same for both languages. In the final stage, the system of grammatical rules becomes differentiated, and the bilingual child can be said to have separate linguistic systems (Volterra \& Taeschner, 1978).

An alternative view to this Unitary Language System Hypothesis is the Dual Language System Hypothesis, stating that children exposed to two languages from birth establish two separate linguistic systems from the onset of acquisition (Genesee, 1989). Under this view, children never go through a stage where their linguistic representations are unified. As will be shown, the literature on bilingual development shows evidence that supports the Dual Language System Hypothesis.

In studies of speech perception, Burns, Yoshida, Hill, and Werker (2007) found that bilingual children were able to perceive language-specific acoustic properties of [p] and [b] in English and French while monolingual children just perceived the differences in French or English, depending on the language of exposure. They concluded that bilingual children were developing these acoustic/phonetic properties in English and French like two monolinguals in one. In an additional study, Sundara, Polka, and Molnar (2008) discovered that infants exposed to French and English were able to perceive [d] in the English specific way at age 10-12 months, while French monolinguals could not. 
These and additional studies suggest that infants exposed to two languages are establishing separate perceptual systems for each language.

Evidence from vocabulary acquisition also supports the Dual Language System Hypothesis. When learning a language, a child needs to recognize familiar word forms in the continuous speech stream. In monolingual children, these word recognition abilities emerge toward the end of the first year of life. Paradis et al. (2010) mention a study that examined word form recognition in English monolingual and Welsh-English bilingual infants ages 9 to 12 months using both behavioral and brain activity measures. The results of this experiment showed that bilingual infants recognized familiar word forms in both languages at the same age as monolingual English children, around 11 months (Vihman, Thierry, Lum, Keren-Portnoy, \& Martin, 2007). An additional study found that, like monolingual children of the same age, 14 month-old bilingual children could successfully learn new words for novel objects in an experimental task (Werker, ByersHeinlein, \& Fennel, 2009).

Relative to syntactic development, Paradis and Genesee (1996) found that bilingual English/French children were developing the grammatical properties of English and French at the same time as monolingual children. For example, in French, children start using agreement morphology at an earlier age than in English. Paradis and Genesee (1996) found that the bilingual children in their experiment started using agreement morphology in French at the same age as monolingual French children and that they started using agreement morphology in English at the same age as monolingual English children. They did not find any evidence of delay or transfer of these grammatical properties. 
Thus, there is no evidence showing that bilingual children are slower than monolingual children to acquire phonology, vocabulary or grammar. Also, there is no systematic evidence that bilingual children are slower than monolingual children to pass through early critical milestones such as babbling and the use of first word combinations (Genesee, 1989).

Nevertheless, there is evidence that language dominance plays a role at the very early stages of children's lexical development. Conboy and Mills (2006) measured the brain activity of 19 to 22 month-old bilingual toddlers while they listened to known and unknown words. They found that the timing and distribution of brain activity to known words was different, depending on whether the word was in the children's dominant or non-dominant language. Language dominance is typically linked to the amount of input the bilingual child receives in each language. One consequence of dominance is that a bilingual child may appear to be less advanced in the nondominant language. For example, Pearson, Fernandez, Lewedg, and Oller (1997) found that Spanish-English bilingual children who receive less than $25 \%$ of their input in Spanish do not become fluent Spanish speakers. In addition, expectations of balanced bilingual development in preschool children may be unrealistic, and it is more likely that bilingual children will be dominant in one language. For this reason, it could be inappropriate to clinically assess a child in their nondominant language (Paradis et al. 2010). In this thesis, bilingual children are assessed in both English and Spanish.

Although, for the most part, bilingual children demonstrate the same stages in their developmental language, from the sound system to grammar as their monolingual peers, they also produce developmental language that has some unique target-deviant 
structures that reflect their dual language systems (Genesee, 1989; Paradis et al. 2010). This phenomenon is referred to as crosslinguistic influence. There are two types of crosslinguistic influence, qualitative and quantitative. Qualitative crosslinguistic influence is characterized by target-deviant structures that are not attested in the monolingual acquisition of the language. On the other hand, quantitative crosslinguistic influence is observed as an increased frequency in the appearance of target-deviant structures that are also evident in a monolingual child's development of that language (Paradis, et al. 2010). In the literature today, there are more examples of quantitative rather than qualitative forms of crosslinguistic influence and the similarities in acquisition patterns between monolingual and bilingual children far outweigh the differences. As Paradis et al. (2010) observe "for professionals dealing with bilingual children, targetdeviant structures that appear to be influenced by the child's other language is typical in bilingual development and is not a sign of confusion or difficulty coping with dual language input" (p. 84).

In summary, developmental stages and patterns are the same overall for monolingual and bilingual children. Research indicates that children have the capacity to acquire two languages without significant costs to the development of early milestones. However, the rate of language development is sensitive to the child's exposure time to each language. Language dominance is expected and typical in the early stages of bilingual language acquisition. 


\subsubsection{Vocabulary Development in Bilingual Children}

Until the 1980's, studies had reported negative effects of bilingualism on lexical measures and several researchers had found that bilingual children showed lower levels of receptive vocabulary than their monolingual peers. Differences between bilingual and monolingual children have been frequently documented in research through the use of standardized vocabulary tests for toddler to school-aged children. Nevertheless, Pearson, Fernandez and Oller (1993) showed that when bilingual children are examined taking into consideration both languages that they are exposed to, there are no major differences in terms of vocabulary size.

Pearson et al. (1993) compared lexical development in a sample of 25 simultaneous bilingual and 35 monolingual children for whom semi-longitudinal data were collected between the ages of 8 and 30 months. A standardized parent form, the MacArthur Communicative Development Inventory (1989), was used to assess children's receptive and productive vocabulary in English and/or Spanish. A methodology was devised to assess the degree of overlap between the bilingual children's lexical knowledge in one language and their knowledge in the other. Using these measures, the researchers found that there was no statistical basis for concluding that the bilingual children were slower to develop early vocabulary than the monolingual children. Their results showed that when the vocabularies of both languages were combined and the translation equivalents were counted only once, their total "conceptual" vocabulary was similar in size to that of monolingual norms.

The wide range of vocabulary sizes observed at the above ages in normally developing children have also been observed in the bilingual children (Fenson, Dale, 
Reznick, et al., 1991). This close correspondence of the pattern of bilinguals' growth in both languages to monolinguals' growth in one suggests that norms for lexical development in bilinguals should be made with reference to the children's performance in the two languages together (Pearson et. al. 1993). These findings indicated that bilingual children's ability to understand two languages might be comparable in each language to monolingual children's.

Thus, it appears that bilingual children use the same mechanisms to acquire words as monolingual children, and therefore, are successful word learners. When bilingual children are compared to monolingual children, the size of their vocabularies in each language might seem smaller, but this depends on the amount of exposure to each language (Paradis et al. 2010).

Volterra and Taeschner (1978) proposed a unified vocabulary in production because of the initial absence of translation equivalents in bilingual children's productive vocabularies. Other studies found that bilingual children have translation equivalents from the earliest stages, although these children should not be expected to have a translation equivalent for absolutely every word (Paradis et al. 2010). As a matter of fact, a bilingual child's development in one language can be advanced by the other, dominant language. This is called bilingual bootstrapping. With this phenomenon, a bilingual child may not have to "discover" all the linguistic concepts twice (Paradis et al. 2010).

Overall, the research on vocabulary development raises the question of whether it is appropriate to expect bilinguals to become identical to monolinguals in all aspects of language development and processing, or whether some differences in the configuration of linguistic competence should be expected between them for vocabulary knowledge 
(Paradis et al. 2010). These authors suggest that it is critical to understand that any kind of difference between bilinguals and monolinguals should not be automatically considered negative. Importantly, when assessing a bilingual child, the dominant language is the one to examine for the upper limits of that child's development (Genesee, 1989). Testing bilingual children in their nondominant language could result in substantial underestimation of the child's linguistic abilities overall and vocabulary size in particular. In effect, clinicians should expect the vocabulary size in each language of a bilingual child to be smaller than that of a monolingual child. Therefore, it is essential to take caution and interpret the results of standaridized vocabulary tests differently for bilingual and monolingual children (Paradis et al. 2010).

In the current experiment, vocabulary comprehension is tested in monolingual and bilingual children with autism using a standardized test norm-referenced to the bilingual Spanish/English population. Thus, differences in vocabulary size between English and Spanish are controlled in this study. 


\subsection{Language Development in Children with Autism}

An individual with ASD is likely to demonstrate certain patterns of language comprehension and expression; pragmatic language use; semantic, syntactic, and morphological understanding; and phonological characteristics (Benson, 2002). Below is an overview of several behaviors typical of individuals with ASD listed by language category. This study will place a significant importance on the semantic patterns of individuals with ASD. Due to individual variability, not all of the behaviors detailed below will be visible in every child (Shipley \& McAfee, 2009).

In regards to their general comprehension and expression, individuals with ASD will present difficulty with language production (Charman, Swettenham, and BaronCohen, 2003). They will exhibit high-pitched, monotonous speech accompanied by echolalia. Their speech is often classified as stereotypic and meaningless. They produce asocial monologues and have a general preference for mechanical sounds rather than human voices (Scott, 2012). They often show preoccupations with favored objects or activities and reduced interest in communication. They may have errors recognizing faces. Often they show poor use of environmental cues and a poor response to commands (Shipley \& McAfee, 2009).

As for their pragmatic behaviors, individuals with ASD often lack responsiveness to others. They have difficulty with topic maintenance in conversation and use only a few communication strategies (Scott, 2012). They show minimal use of gestural communication and have a lack of knowledge of speaker and listener roles. They lack eye contact and have difficulty with topic shifts. These individuals have a preference for solitude and a reluctance to be touched, hugged, or held (Shipley \& McAfee, 2009). 
Relative to the concept of Theory of Mind (TOM), a person's ability to understand that people engage in mental processes, such as cognitive knowledge and emotion, separate from their own, individuals with ASD may have particular delays and deficits in the development of the ability to "read another's mind" (TOM) (Shipley \& McAfee, 2009). Individuals with ASD have unique syntactic and morphological patterns. They often reverse pronouns and have difficulties with morphological agreement such as plurals, possessives, and verb tenses (Stone et al. 1998). They overuse one or two basic sentence patterns and generally use only simple and short sentence structure. They often show difficulty with word order and omit grammatical morphemes (Shipley \& McAfee, 2009).

Individuals with ASD have variable phonological patterns. They show some articulation disorders and have delayed acquisition of speech sound production, although appropriate speech patterns develop over time (Benson, 2002). They may also exhibit exaggerated articulation and show difficulty with sound segmentation and knowledge of word boundaries (Shipley \& McAfee, 2009).

Most importantly with regards to this study, individuals with ASD show unique semantic patterns. These are characterized by a slow acquisition of speech and wordfinding difficulties. Also, these individuals show faster learning of concrete words than abstract words, particularly those abstract words that refer to human relations or emotions (Benson, 2002). They often have trouble using correct names of other people and have a restricted use of word meanings or lack of word generalization. They exhibit poor categorization abilities as well as poor understanding of related words (Shipley \& McAfee, 2009). 
Recently, a study that examined early vocabulary development in this population found delays in receptive vocabulary and phrase understanding as well as expressive vocabulary (Charman, Drew, Baird, \& Baird, 2003). This study also validated the use of a parent report, MacArthur Communicative Development Inventory (Fenson, et al., 1993), for assessing the language level of children with autism who demonstrated language delay. 


\subsection{Language Development of Bilingual Children with Autism}

There is little understanding of the process of bilingual language development in children with autism (Seung, Siraj, \& Elder, 2006). However, anecdotally, it is known that many children with autism learn to understand more than one language (Lord, 1995). As with other developmental conditions, autism affects all languages of a bilingual child in the same way (Dopke, 2006). There is no research evidence to suggest that hearing more than one language makes the symptoms of autism worse or that the English-only language used in the home improves the language or social abilities of children with autism (Dopke, 2006).

However, the overall impact of bilingual exposure on language learning has not been systematically studied in children with ASD. A recent study conducted by Hambly and Fombonne (2012) compared the social abilities and language levels of children (mean age $=56$ months) with ASD from bilingual $(\mathrm{n}=45)$ and monolingual $(\mathrm{n}=30)$ environments. Bilingually-exposed children were subgrouped based on simultaneous bilingual exposure from infancy versus sequential post-infancy bilingual exposure. Therefore, the two groups of children were sequential bilinguals, versus those exposed to different language environments simultaneously or, simultaneous bilinguals. Despite significantly different amounts of bilingual exposure across all groups, there were no significant group differences between monolingual and bilingual children with ASD in terms of language level (Hambly \& Fombone, 2012). In conclusion, bilingually-exposed children with ASD did not experience additional delays in language development. 


\section{SUMMARY}

In summary, children with autism tend to be delayed in typical language development milestones, such as babbling and speaking. Children with autism may also present difficulties in combining words into meaningful sentences, may speak only single words, or repeat the same phrase over and over. They may also go through a stage in which they repeat what they hear (echolalia). Language abilities in children with autism are generally assessed using standardized vocabulary tests.

The aim of this thesis is to measure language comprehension abilities in children with varying degrees of autism using a standardized test and the eye-tracker technique. The dependent variable is the number of words correct on each examination. The results of both tests are then compared to determine differences in results. The participant data is also examined in terms of language exposure and autism severity in order to understand in which cases the eye-tracker can be a helpful tool in the assessment of these children. Given the social interaction problems characteristic of ASD, we hypothesized that the language capacities of these children are not completely assessed using traditional tests and that eye-tracker could help in the assessment of these children. 
III. METHODOLOGY 


\subsection{Purpose:}

This study was designed to examine vocabulary comprehension abilities in monolingual and bilingual children with varying degrees of autism using the eye-tracker technique. Language abilities in children with autism are generally assessed using vocabulary tests like the Receptive One-Word Picture Vocabulary Test (ROWPVT). Nevertheless, these tests require an interaction between the Speech Language Pathologist and the client because the child is expected to point to pictures. For example, the child is shown pictures of a tree, a boy, a man and a tie and upon listening to a sentence like "Which picture shows a man?" the child is supposed to point to the picture depicting a man. Given the social interaction problems characteristic of children with ASD, it could be the case that the language capacities of these children are not completely assessed because they are required to interact and point to pictures.

Eye-tracker captures and records children's eye movements and could help in the assessment of language abilities in children with autism because it does not require any interaction or pointing. Thus, the eye-tracker could yield a more accurate measure of children's language comprehension abilities.

\subsection{Hypothesis:}

Because children with ASD present social interaction problems, we hypothesized that the language capacities of these children are not completely assessed using traditional tests, and that the eye-tracker could help in the assessment of vocabulary comprehension in these children. The dependent variable being measured is the number of words correct. 


\subsection{Participants:}

To better understand the role of eye-tracker technique in the assessment of vocabulary comprehension in children with ASD, we examined a diverse population of children with ASD, ages 3 to 9, in terms of language background (monolingual and bilingual) and disorder severity (mild, moderate and severe). Twelve monolingual English children with mild to moderate autism, and 4 children ( 2 monolingual English, and 2 bilingual Spanish/ English) with severe autism (mean age 5.4) living in the Miami, Florida area, were tested. Four monolingual typically developing children, (mean age 6.0) were also tested as a control group. Below a table of the participants demographics is explained. This information was obtained from the participants parents and from the Hawkes Bluff Elementary school psychologist's diagnostic records.

\begin{tabular}{|l|l|l|l|l|l|l|}
\hline SUBJECT & \multicolumn{1}{|c|}{ SEX } & AGE & $\begin{array}{l}\text { AUTISM } \\
\text { SPECTRUM }\end{array}$ & $\begin{array}{l}\text { VERBAL } \\
\text { ABILITY }\end{array}$ & $\begin{array}{l}\text { LANGUAGE } \\
\text { EXPOSURE }\end{array}$ & $\begin{array}{c}\text { LOCATION } \\
\text { TESTED }\end{array}$ \\
\hline AR & Male & $8 \mathrm{y}, 10 \mathrm{~m}$ & Severe & $\begin{array}{l}\text { Non- } \\
\text { Verbal }\end{array}$ & $\begin{array}{l}\text { English \& } \\
\text { Spanish }\end{array}$ & FIU Lab \\
\hline MR & Male & $5 \mathrm{y}, 0 \mathrm{~m}$ & Severe & $\begin{array}{l}\text { Mildly } \\
\text { Verbal }\end{array}$ & $\begin{array}{l}\text { English \& } \\
\text { Spanish }\end{array}$ & FIU Lab \\
\hline AP & Male & $4 \mathrm{y}, 7 \mathrm{~m}$ & Severe & $\begin{array}{l}\text { Non- } \\
\text { Verbal }\end{array}$ & English & Hawkes Bluff \\
\hline AC & Male & $3 \mathrm{y}, 8 \mathrm{~m}$ & Severe & $\begin{array}{l}\text { Mildly } \\
\text { Verbal }\end{array}$ & English & Hawkes Bluff \\
\hline JG & Male & $9 \mathrm{y}, 4 \mathrm{~m}$ & Mild & Verbal & English & Hawkes Bluff \\
\hline NR & Male & $9 \mathrm{y}, 2 \mathrm{~m}$ & Moderate & Verbal & English & Hawkes Bluff \\
\hline JC & Male & $9 \mathrm{y}, 0 \mathrm{~m}$ & Moderate & Verbal & English & Hawkes Bluff \\
\hline CC & Male & $7 \mathrm{y}, 10 \mathrm{~m}$ & Mild & Verbal & English & Hawkes Bluff \\
\hline AT & Male & $3 \mathrm{y}, 10 \mathrm{~m}$ & Moderate & $\begin{array}{l}\text { Non- } \\
\text { Verbal }\end{array}$ & English & Hawkes Bluff \\
\hline DL & Male & $4 \mathrm{y}, 10 \mathrm{~m}$ & Mild & $\begin{array}{l}\text { Non- } \\
\text { Verbal }\end{array}$ & English & Hawkes Bluff \\
\hline RL & Male & $5 \mathrm{y}, 1 \mathrm{~m}$ & Mild & Verbal & English & Hawkes Bluff \\
\hline BL & Male & $5 \mathrm{y}, 1 \mathrm{~m}$ & Mild & Verbal & English & Hawkes Bluff \\
\hline
\end{tabular}




\begin{tabular}{|l|l|l|l|l|l|l|}
\hline EV & Female & $4 \mathrm{y}, 5 \mathrm{~m}$ & Mild & Verbal & English & FIU Lab \\
\hline NF & Male & $7 \mathrm{y}, 0 \mathrm{~m}$ & Moderate & Verbal & English & FIU Lab \\
\hline MP & Male & $3 \mathrm{y}, 11 \mathrm{~m}$ & Moderate & $\begin{array}{l}\text { Non- } \\
\text { Verbal }\end{array}$ & English & FIU Lab \\
\hline AS & Female & $5 \mathrm{y}, 7 \mathrm{~m}$ & Mild & Verbal & English & FIU Lab \\
\hline \multicolumn{7}{|c|}{ TYPICALLY DEVELOPING CONTROL GROUP } \\
\hline TY & Female & $5 \mathrm{y}, 9 \mathrm{~m}$ & No ASD & Verbal & English & Hawkes Bluff \\
\hline NC & Male & $6 y, 0 \mathrm{~m}$ & No ASD & Verbal & English & Hawkes Bluff \\
\hline EM & Female & $6 y, 2 \mathrm{~m}$ & No ASD & Verbal & English & Hawkes Bluff \\
\hline MP & Male & $6 y, 1 \mathrm{~m}$ & No ASD & Verbal & English & Hawkes Bluff \\
\hline
\end{tabular}

Language dominance was established using a questionnaire included in the ROWPVT test and a more detailed questionnaire that was developed in the CSD Psycholinguistics Laboratory at FIU, based on the questionnaires used by Bosch and Sebastian-Galles (2001). The detailed questionnaire was completed by the parent before the test was administered. Pearson, Fernandez, Lewedge, and Oller (1997) showed that Spanish-English bilingual children who received less than $25 \%$ of their input in Spanish, often did not achieve bilingual success. Thus, a child was considered monolingual Spanish if 76\%- 100\% input was received in Spanish, and 0\%-24\% input was received in English. A child was considered Spanish dominant if 75\%-60\% input was received in Spanish, and 25\%-40\% input was received in English. A child was classified as a balanced bilingual if 59\%- 41\% input was received in Spanish, and 41\%- 59\% input was received in English. A child was considered English dominant if 40\%- 25\% input was received in Spanish, and 60\%- 75\% input was received in English. Monolingual English children received 76\%- 100\% input in English, and 0\%-24\% input in Spanish.

All participants' parents gave permission to participate in the experiment. Please refer to Appendices B and C for the approved IRB and research consent form. 


\subsection{Stimuli and Apparatus:}

Language comprehension abilities in monolingual and bilingual children with ASD were tested using a standardized test, the Receptive One Word Picture Vocabulary Test (English and Spanish Bilingual Edition) (Brownell, 2000, $2^{\text {nd }}$ Edition). This test is norm-referenced for bilingual Spanish/ English children. In this test, for each target word, the child looks at four different pictures (e.g. a tree, a boy, a man and a tie) and a question about the target word (e.g. which picture shows a man?) is asked by the person assessing the child. Then, the child is supposed to point to one of the pictures.

All the picture images from the ROWPVT standardized test were scanned and formatted to be used with a TOBII T120 eye-tracker device. This eye-tracker system is a non-invasive table-mounted system in which the participant sits in a chair in front of the eye-tracker monitor screen with no attachments to his or her body. This particular system is very useful in studies involving children who cannot yet speak and are still developing motor and other related skills. In language processing, eye movements are closely linked to the current focus of attention (Blakemore, 2009). Therefore, eye tracking provides valuable input in linguistic research. By analyzing what children look at, it is possible to find out what they understand from the language they hear around them or from situations presented to them visually (Scott, 2012). The eye-tracker monitor screen is equipped with a system that captures and records the participant's eye gaze, allowing for simple automatic coding of eye position. This method is most appropriate for participants sensitive to touch or who might mishandle or damage eye-tracking equipment in close proximity. 
The child was presented with the pictures on the monitor and listened to a Noun Phrase (e.g. man) recorded by a female voice at the same time. More details on eyetracker methodology and its usefulness in psycholinguistics research is explained below.

\section{Eye- Tracker Technology}

Cooper (1974) was the first to use eye movements as a real-time measure of adults spoken language processing abilities. In a series of eye tracking experiments, he observed that adult listeners rapidly fixate pictures depicting the referents of heard speech. These studies demonstrated that eye movements can be used to trace the time course of adult language comprehension, production, and even dynamic conversation (Henderson \& Ferreira 2004, Trueswell \& Tanenhaus 2005). Since then, the development of accurate head-mounted and remote eye tracking systems have made it possible to conduct similar visual world studies with young children. Today there are several types of eye tracking systems in common use (Duchowski, 2003). Electro-oculography (EOG) is a technique by which electrodes are placed on the skin around the eyes and the difference in surface potential is used to calculate the current position of the eye. The mounting of electrodes on the skin however, is somewhat time-consuming and often not tolerated by certain subject populations, such as children or individuals with mental disorders (Brunelli \& Poggio, 1993). Another method is head mounted systems that use highly miniaturized cameras and optics mounted on a visor. In these systems, the video output from the eye camera is analyzed in real time to calculate the current location of the pupil and the center of the corneal reflection. Through an initial calibration procedure, coordinates are mapped onto coordinates in the scene video. This procedure is often 
difficult to use with children because it requires the child to hold his/her head still while fixating a target location in the world.

To bypass this problem, the current study will use the second type of eye tracker system available, known as remote eye tracking systems. The TOBII, works like a headmounted system, however the optics are housed off the head, requiring no visor. This video-based pupil/corneal reflection eye tracking device is one of the most common eye tracking systems in use today. This system tracks the head using video-based methods. It relies on video localization of the pupil in conjunction with infrared illumination. These systems are becoming extremely popular because they can be much easier to use with toddlers and young children (Aslin \&McMurray, 2004; Johnson, Slemmer, \& Amso, 2004). These remote systems map direction of gaze directly onto the coordinates of a computer video display, allowing for simple automatic coding of eye position. A typical setup consists of a camera focused on the area around the eye of the subject and one or more infrared sources for creating corneal reflections (SensoMotoric Instruments (SMI), 2006). The eye camera is connected to a computer, which localizes the pupil and corneal reflections in the incoming video stream. The face of the subject is frontal-facing and centered in the video stream (Brunelli \& Poggio, 1993). In an eye-only infrared video stream such as the TOBII, the pupil is detected by locating dark regions in the eye. Next, the largest region is selected as the pupil and the centroid of this mass is taken as the pupil center (Lowe, 1999).

In the current experiment, the same pictures used in the traditional vocabulary test will appear on the eye-tracker monitor, and the eye-tracker system will record the child's eye movements. Data analysis can then be performed on the resulting gaze record. The 
study of gaze behavior has long been used to investigate how stimuli are processed. The premise behind this is that when a person looks directly at an object, or fixates, its image falls on the fovea, the part of the retina specialized for detailed visual processing (Scott, 2012). Recordings of gazed behavior indicate where in a visual scene a person seeks detailed information. A fixation occurs when the observer looks at the same point for long enough to allow the processing of visual information from that point (Scott, 2012). For each trial of interest, the child's direction of gaze is linked to the onset of critical speech events, or onset of critical words in a sentence (e.g., nouns) and then averaged across trials and participants. Fixation proportions are obtained by determining the proportion of looks to the alternative objects at each time slice and show how the pattern of looks to objects changes as the sentence unfolds. The proportion of looks to objects, the time spent looking at the alternative objects, and the number and/or proportion of looks generated to objects in this time region can then be analyzed. These different measures are all highly correlated but offer slightly different pictures of the eye movement record.

Eye tracking allows the direct, objective and quantitative observation of behavior, and through the analysis of fixation patterns, can indicate which information from a scene is available to the brain (Scott, 2012). It is important to note caution and care when performing research with eye tracker technology because developmental changes in attentional control and cognitive control can interact with observations made from this method. However, this concern is true of any experimental method when applied to the study of development (Trueswell, 2004). Therefore, the researcher must take caution to understand and seek out interactions in the experimental findings. 


\subsection{Design:}

The within-subject factor was test type (ROWPVT, eye-tracker). The dependent variable was number of words correct (measured by pointing to the right picture in the ROWPVT test and by total fixation time to the correct word in the eye-tracker experiment). It was determined that the child looked at the correct word if there was a difference of at least 200 milliseconds in looking time between the correct word and the other 3 choices. In other words, the child must look at the correct word for 200 milliseconds longer than the other 3 possible choices. The total amount of fixation time on an area of interest (AOI) is defined by the Tobii instructions' manual as the duration of all fixations within an AOI or within all areas of interest belonging to an area of interest group.

\subsection{Procedure:}

Six children came to the CSD Psycholinguistics Laboratory for approximately forty-five minutes. Ten children were tested in their school, Hawkes Bluff Elementary. Additionally, four typically developing control children were also tested at this elementary school. In this case the eye-tracker device was brought to the school and the children were tested in a room reserved for the experiment for approximately forty-five minutes. Each child was tested individually, first using the eye-tracker and then on the paper and pencil standardized test (ROWPVT). Before starting the test, language exposure was determined.

Eye-Tracker Test: 
The child sat in front of a computer monitor specially designed to track eye movements when stimuli (e.g. pictures) were presented on the screen. When tested at the Psycholinguistics Lab, the child sat on the mother's lap. In this way, the mother could help the child pay attention to the stimuli and not touch the equipment. When tested at school, one of the experimenters or the teacher helped the child pay attention to the pictures by inviting them to look at the screen. In some cases, the child sat on the teacher's lap. This procedure difference did not impact the results since the chair had to be adjusted at a height that allowed the eye-tracker to successfully track their eye movements. Before the experiment started the experimenter automatically calibrated the child's eyes so that the eye-tracker could accurately track eye gaze. Then, the child was presented with four color pictures at a time on the computer screen simultaneously with an orally presented word that matched one of the pictures. The child's eye movements were recorded in order to determine which picture the child looked at when presented with the oral stimuli. The experiment finished when the child was not able to concentrate and look at the screen any longer.

The bilingual English/Spanish participants were tested first in their dominant language and then in their non-dominant language. In this case, they participated in two eye-tracker sessions, with an interval of approximately 2 weeks between the sessions.

\section{ROWPVT Test:}

After a short break, the child was tested using the standardized, paper and pencil test (ROWPVT) that is used to measure children's vocabulary comprehension. In this test, they were presented with the same four color pictures per plate as seen on the 
computer screen, except this time, they were asked to point to a picture when the oral stimuli was presented. Different from the test instructions, the test started at word one and not at the word that corresponded to the chronological age of the child. This option allowed the child to be presented with the same stimuli on the ROWPVT test and on the eye-tracker experiment.

With bilingual children, after the participant was tested on the eye-tracker in their dominant language, the ROWPVT- Spanish Bilingual Edition test was administered. In this case, the test administrator first said the target word in the dominant language and if the participant did not answer the question correctly, the word was then presented in the non-dominant language. If the child answered correctly in one language, this language was identified by the examiner when recording the scores. Please refer to Appendix F for the full-length questionnaire. For more details on the administrating procedures, standardization and reliability and validity of the ROWPVT- Receptive One-Word Picture Vocabulary Test, see Appendix A.

The results of the ROWPVT test were then compared to the eye-tracker results. In the next section an analysis of these results is presented. 


\section{CHAPTER IV. RESULTS}

Data were collected from sixteen children with ASD, 12 monolingual children with mild to moderate autism, and 4 children with severe ASD (2 monolingual English and 2 bilingual English/Spanish), as well as four typically developing, monolongual control children. The data were analyzed and both the eye-tracker data and the ROWVPT data were compared. The participants' data were also examined in terms of language exposure and autism severity in order to understand in which cases eye-tracker can be a helpful tool in the assessment of these children.

The results show that the 4 control children and the 12 monolingual children with mild to moderate autism had better performance in the ROWPVT test than on the eyetracker test. The two monolingual children with severe autism could not be calibrated. Thus, we cannot present eye-tracker data from these children. The two bilingual children with severe ASD had better results using the eye-tracker than the ROWPVT. One child (AR) showed better results in Spanish and the other child (MR) showed better results in English. In both cases, better results were found in the language they did worse on in the ROWPVT test. When tested in English, participant AR had 11 correct words in the ROWPVT test and 5 correct words on the eye-tracker test. When tested in Spanish this pattern reversed and he had 2 correct words on the ROWPVT test and 7 correct words on the eye-tracker. In the case of MR, when he was tested in English he had 1 correct word on the ROWPVT test and 8 correct words on the eye-tracker test. When tested in Spanish, he showed the opposite pattern, with 8 correct words on the ROWPVT test and 2 correct words on the eye-tracker. In terms of verbal ability AR was non-verbal and MR 
was mildly verbal. Nevertheless, these results cannot be explained by verbal ability because some children with mild to moderate ASD were also non-verbal.

Because eye-tracker results could not be obtained from the two monolingual children with severe autism, we do not know whether these children would present better performance in the eye-tracker test than in the ROWPVT test. Thus, we do not know if the eye-tracker can be a helpful tool in the assessment of children with severe ASD independent of language exposure (monolingual and bilinguals). Our results suggest that at least with bilingual children with severe ASD, eye-tracker was useful in the assessment of these children's vocabulary.

The tables below show the total number of words each participant with severe $\mathrm{ASD}$, mild to moderate ASD, and the control group answered correctly in the paper and pencil test (ROWPVT), the eye-tracker test (total fixation duration time), and the number of words answered correctly on both the ROWPVT test and in the eye-tracker test. Additional demographic information about each participant was previously presented and can be found in the participant section, 3.3.

\section{$\underline{\text { Severe ASD }}$}

The first two participants are bilingual children (AR and MR). Both of these children are balanced bilinguals, and received 59\%- 41\% of input in Spanish, and 41\%$59 \%$ of input in English. The other two participants are monolingual children (AP and AC) and only received input in English. These monolingual severe children could not be conditioned to the eye-tracker device and therefore their results are only displayed for the 
paper and pencil English administration. The participants with severe ASD's results are presented in the table below.

\begin{tabular}{|c|c|c|c|c|c|c|c|}
\hline Subject & $\begin{array}{c}\text { Language } \\
\text { Exposure }\end{array}$ & \multicolumn{3}{|c|}{ English Results } & \multicolumn{3}{c|}{ Spanish Results } \\
\cline { 2 - 7 } & $\begin{array}{c}\text { Total \# } \\
\text { of } \\
\text { Words } \\
\text { Correct } \\
\text { on the } \\
\text { Paper } \\
\text { \&Pencil }\end{array}$ & $\begin{array}{c}\text { Total \# } \\
\text { of } \\
\text { Words } \\
\text { Correct } \\
\text { on the } \\
\text { Eye- } \\
\text { Tracker }\end{array}$ & $\begin{array}{c}\text { Total \# } \\
\text { of } \\
\text { Words } \\
\text { Correct } \\
\text { on Both } \\
\text { the P\&P } \\
\text { and ET }\end{array}$ & $\begin{array}{c}\text { Total \# } \\
\text { of } \\
\text { Words } \\
\text { Correct } \\
\text { on the } \\
\text { Paper } \\
\text { \&Pencil }\end{array}$ & $\begin{array}{c}\text { Total \# } \\
\text { of } \\
\text { Words } \\
\text { Correct } \\
\text { on the } \\
\text { Eye- } \\
\text { Tracker }\end{array}$ & $\begin{array}{c}\text { Total \# } \\
\text { of } \\
\text { Words } \\
\text { Correct } \\
\text { on Both } \\
\text { the P\&P } \\
\text { and ET }\end{array}$ \\
\hline AR & $\begin{array}{c}\text { English \& } \\
\text { Spanish }\end{array}$ & 11 & 5 & 2 & 2 & 7 & 1 \\
\hline MR & $\begin{array}{c}\text { English \& } \\
\text { Spanish }\end{array}$ & 1 & 8 & 1 & 8 & 2 & 1 \\
\hline AP & English & 21 & 0 & 0 & & & \\
\hline AC & English & 13 & 0 & 0 & & & \\
\hline
\end{tabular}

Mild to Moderate ASD

All the participants with mild to moderate ASD were also monolingual. Thus, only English results are presented in the table below.

\begin{tabular}{|c|c|c|c|}
\hline \multirow{2}{*}{ Subject } & \multicolumn{3}{|c|}{ English Results } \\
\cline { 2 - 4 } & $\begin{array}{c}\text { Total \# of Words } \\
\text { Correct on the } \\
\text { Paper \&Pencil }\end{array}$ & $\begin{array}{c}\text { Total \# of Words } \\
\text { Correct on the } \\
\text { Eye- Tracker }\end{array}$ & $\begin{array}{c}\text { Total \# of Words } \\
\text { Correct on Both the } \\
\text { P\&P and ET }\end{array}$ \\
\hline JG & 96 & 57 & 48 \\
\hline NR & 102 & 24 & 18 \\
\hline JC & 81 & 14 & 14 \\
\hline CC & 96 & 44 & 44 \\
\hline AT & 39 & 10 & 3 \\
\hline DL & 12 & 4 & 3 \\
\hline RL & 61 & 16 & 16 \\
\hline BL & 55 & 17 & 5 \\
\hline EV & 37 & 5 & 3 \\
\hline NF & 32 & 8 & 4 \\
\hline MP & 20 & 4 & 25 \\
\hline AS & 73 & 28 & \\
\hline
\end{tabular}




\section{Control Group}

Children in the control group were all monolingual English speakers. Only English data is presented below.

\begin{tabular}{|c|c|c|c|}
\hline \multirow{2}{*}{ Subject } & \multicolumn{3}{|c|}{ English Results } \\
\cline { 2 - 4 } & $\begin{array}{c}\text { Total \# of Words } \\
\text { Correct on the } \\
\text { Paper \&Pencil }\end{array}$ & $\begin{array}{c}\text { Total \# of Words } \\
\text { Correct on the } \\
\text { Eye- Tracker }\end{array}$ & $\begin{array}{c}\text { Total \# of Words } \\
\text { Correct on Both the } \\
\text { P\&P and ET }\end{array}$ \\
\hline TY & 76 & 43 & 40 \\
\hline NC & 81 & 33 & 31 \\
\hline EM & 81 & 40 & 38 \\
\hline MP & 68 & 55 & 50 \\
\hline
\end{tabular}

In conclusion, our data shows that with severe cases of autism, at least in bilingual children, the eye-tracker can be a helpful tool in the assessment of these children's vocabulary. We are unable to claim anything about the monolingual children with severe ASD tested at Hawkes Bluff Elementary school because they were unable to be calibrated and therefore could not be tested on the eye-tracker. 
CHAPTER V. DISCUSSION 


\subsection{Components of Investigation}

The aim of this thesis was to examine vocabulary comprehension in children with varying degress of ASD using two different measures: a standardized language comprehension test (ROWPVT) and eye-tracker methodology. Because eye-tracker does not require elicitation and an interaction with the experimenter, we examined whether some of these children would have a better performance on the eye-tracker experiment than on the standardized test administration.

The study helps to understand whether eye-tracker could be an efficient language measure with any type of children with ASD, independent of autism severity and language exposure. Thus, we tested 4 typically developing control children, 14 monolingual English children with mild to moderate autism, and 4 children (2 monolingual English, 2 bilingual Spanish/English) with severe autism. In our findings, it was the case that eye-tracker was useful with bilingual children with severe autism. In fact, monolingual English children with mild to moderate autism, who performed at the ceiling on the standardized test, did not present a better performance on the eye-tracker test. 


\subsection{General Discussion}

The comparison of the eye-tracker data and the standadardized test data might be useful not only to more effectively understand the vocabulary capacities of these children but also to evaluate these testing measures and their efficiency taking into consideration various aspects of the children's disorders and language background.

As previously mentioned, given the social interaction problems characteristic of ASD, we hypothesized that the language capacities of these children are not completely assessed using traditional tests requiring elicitation and that the eye-tracker could help in the assessment of these children. Although we did not find better performance on the eye-tracker test than on the ROWPVT test with children with mild/moderate autism, we cannot rule out the efficacy of the eye-tracker as a testing measure with this population either. Because many of these children showed a lack of interest to the device and became restless and unengaged in the eye-tracker test, it might be that if changes in the presentation of stimuli are implemented, the eye-tracker could still be a useful testing measure with this population of ASD children. 


\subsection{Limitations}

Because of today's current technology, including computers, iPad apps, television shows and interactive games that many children with autism are exposed to, the static stimuli of the eye-tracker possibly appeared to be less engaging to them. Because the eye-tracker images are static, it might be that these children lost focus and attention

during the eye-tracker test. They often looked away from the device, yawned and asked if they were almost finished. The scanned images of the ROWPVT test may be 'boring', accompanied by a recorded monotoned voice asking the child to repeatedly look at pictures. The ROWPVT test also gives more freedom to the test administrator in that they can use more engaging intonation voicing patterns and facial expressions to encourage the child to generate a response. Also, when the children begin to get restless the administrator can manipulate the testing booklet closer to their eyes, or change the position of their chair to redirect the child. These changes cannot be implemented in the eye-tracker test.

Regarding language exposure, we cannot claim that eye-tracker should be used only with bilingual children with severe ASD either, because the two monolingual, severe children at Hawkes Bluff Elementary were fussy and could not be calibrated. In general, it was more difficult to calibrate children with severe autism. The same difficulty was found with children tested in the CSD Psycholinguistics Lab. Nevertheless, in the FIU lab we were able to test two bilingual children with severe autism. These two balanced bilingual children with severe autism had better results using the eye-tracker than the ROWPVT. These results suggest that eye-tracker can be a valuable tool to examine vocabulary in bilingual children with severe autism. 


\subsection{Implications for Future Research}

In future studies the eye-tracker stimuli presentation could be manipulated in order to be more engaging to children with mild to moderate ASD. Another possibility is to use eye-tracker as a complementary language measure for these children. In this case, in the eye-tracker test, children would be presented only to the pictures and words they did not answer correctly on the ROWPVT test. This might increase the chances of better understanding the amount of vocabulary these children know. The CSD Psycholinguistics Lab at FIU plans to explore both of these possibilities.

Interestingly, the bilingual children with severe autism showed better performance on the eye-tracker test in the language they did worse on the ROWPVT test. One child (AR) showed better eye-tracker results in Spanish and the other child (MR) showed better eye-tracker results in English. Thus, in both cases, better results were found in the language they did worse on in the ROWPVT test. For these two children at least, the eyetracker was a complementary tool to assess vocabulary comprehension. Because both children were balanced bilinguals, future studies should also examine whether better eyetracker results are found in the non-dominant or dominant language of bilingual children, or whether dominance is not a factor when assessing vocabulary using the eye-tracker. In other words, it needs to be established whether or not language dominance is a factor in assessing vocabulary in bilingual children with severe ASD.

This thesis contributed to a better understanding of how to assess vocabulary development in children with ASD. By using a traditional test (ROWPVT) and the eyetracker technique, and testing children with varying degrees of ASD severity and language exposure, we could examine how these different testing techniques interact in 
the vocabulary assessment of children with ASD and which factors might be relevant in this interaction. Future work needs to clarify some of these factors, but our results show that bilingual children with severe ASD had better results on the eye-tracker test in the language they did worse on in the traditional test. These results suggest that the eyetracker can be a valuable tool to examine vocabulary in bilingual children with severe autism and that these children know more vocabulary than traditional test measures indicate. 


\section{CHAPTER VI. CONCLUSION}

In the autism language development research, it is not clear how much language a child with autism knows and how to assess language abilities in this population. In this thesis, vocabulary comprehension was examined using a traditional paper and pencil test (ROWPVT) and the eye-tracker technique, with the aim of contributing to a better understanding of these children's language capacities.

Children with ASD are often diagnosed as having language disorders due to their lack of expressive language capabilities. They are often classified as quiet or reserved relative to communicating. However, this does not mean that they are not able to develop language representations or that they do not have the ability to understand and process language. By examining receptive language skills independent of required elicitation, the results of this thesis contributed to a better understanding of these children's vocabulary comprehension and knowledge.

The results of this thesis showed that bilingual children with severe autism had better results using the eye-tracker than the traditional test in the language they did worse on in the ROWPVT test, suggesting that the eye-tracker can contribute to the assessment of vocabulary in bilingual children with severe autism.

Future work should examine in more detail how to use eye-tracker to assess vocabulary in mild to moderate cases of ASD and whether monolingual children with ASD can also show benefits by being tested using the eye-tracker technique. 


\section{REFERENCES}

American Psychiatric Association. (2000). Diagnostic and Statistical Manual of Mental Disorders. $4^{\text {th }}$ ed. Washington, DC: American Psychiatric Association.

Apel, K., \& Masterson, J. (2001). Beyond Baby Talk. Roseville, CA. Prima Publishing.

Aslin, R. N. \& McMurray, B. (2004). Automated corneal-reflection eye-tracking in infancy: Methodological developments and applications to cognition. Infancy, $6,155-163$.

Benson, G. (2002, November). Autism Spectrum Disorders: Early Identification. Presentation at the annual convention of the American Speech-Language Hearing Association, Atlanta, GA.

Blakemore, S.J. (2009). Eye tracking exploring the gaze attention of autistic children. Eyetrackingupdate.com/2009/12/22/eye-tracking-exploring-the-gaze attention-of-autistic-children/.

Bloom, P. (2002). How children learn the meanings of words. Cambridge, MA: MIT Press.

Bloom, P. \& Markson, L. (1998). Capacities underlying word learning. Trends in Cognitive Sciences 2, 67-73.

Brownell, Rick. (2000). Receptive One-word Picture Vocabulary Test. 2nd ed. Novato, CA: Academic Therapy Publications. Print.

Brunelli, R. \& T. Poggio (1993), Face Recognition: Features versus Templates, IEEE Transactions on PAMI, 15(10):1042-1052.

Burns, T.C., Yoshida, K.A., Hill, K., \& Werker, J. (2007). The development of phonetic representation in bilingual and monolingual infants. Applied Psycholinguistics, 28, 455-474.

Chapman, R. (2000). Children's Language Learning: An Interactionist Perspective. Journal of Child Psychology and Psychiatry, 41, 33-54.

Charman, T., Drew, A., Baird, C., \& Baird, G. (2003). Measuring early language development in preschool children with autism spectrum disorder using the MacArthur Communication Developmental Inventory (infant form). Journal of Child Lanugage, 30. 213-236.

Charman, T., Swettenham, J., Baron-Cohen, S., Cox, A., Baird, G., \& Drew, A. 
(1997). Infants with Autism: An Investigation of Empathy, Pretend Play, Joint Attention and Imitation. Developmental Psychology, 33, 781-789.

Clark, E. (1993). The lexicon in acquisition. New York: Cambridge University Press.

Conboy, B., \& Mills, D. (2006). Two languages, one developing brain: Event-related potentials to words in bilingual toddlers. Developmental Science, 9, F1-F12.

Cooper, R. (1974). The control of eye fixation by the meaning of spoken language: A new methodology for the real-time inventory of speech perception, memory, and language processing. Cognitive Psychology, 6. 84-107.

Dopke, S. (2006). Is bilingualism detrimental for children with autism? Australia University.

Duchowski, A. (2003). Eye Tracking Methodology: Theory \& Practice.

Fenson, L., Dale, P.S., Reznick, J.S., Thal, D., Bates, E., Hartung, J.P., Pethnick, S., \& Reilly, J.S., (1991). Technical manual for the MacArthur Communicative Developmental Inventories. San Diego, CA: San Diego State University.

Filipek, P.A. (2000). Practice Parameter: Screening and Diagnosis of Autism: Report of the Quality Standards Subcommittee of the American Academy of Neurology and the Child Neurology Society. Neurology, 55, 468-479.

Gard, A., Gilman, L., \& Gorman, J. (1993). Speech and language development chart. $2^{\text {nd }}$ ed. Austin, TX: Pro-Ed.

Genesee, F. (1989). Early bilingual development: One language or two? Journal of Child Language, 6, 161-179.

Goldfield, B. (2000). Nouns before verbs in comprehension verses production: The view from pragmatics. Journal of Child Language 7. 501-20.

Goldfield, B. \& Reznick, J. (1990). Early lexical acquisition: Rate, content, and the vocabulary spurt. Journal of Child Language 17. 171-84.

Hambly, C., \& Fombonne, E. (2012). The impact of bilingual environments on language development in children with autism spectrum disorders. Department of Psychiatry, Montreal Children's Hospital, McGill University. Montreal, Canada.

Hedge, M. N. (2001). Introduction to communicative disorders. $3^{\text {rd }}$ ed. Austin, TX: Pro Ed. 
Henderson, J. M., \& Ferreira, F. (2004a). The interface of language, vision, and action: Eye movements and the visual world. New York: Psychology Press.

Henderson, J. M., \& Ferreira, F. (2004b). Scene perception for psycholinguistics. In J. M. Henderson, \& F. Ferreira (Eds.), The interface of language, vision, and action: Eye movements and the visual world (pp. 1-58). New York: Psychology Press.

Johnson, S. P., Amso, D., \& Slemmer, J. A. (2003). Development of object concepts in infancy: Evidence for early learning in an eye tracking paradigm. Proceedings of the National Academy of Sciences (USA), 100, 10568-10573.

Koope, T. M, Eaves, L. C., \& Ho. H. H. (2001). Screening for Autism and Pervasive Developmental Disorders in Very Young Children. British Columbia Medical Journal, 43(5), 266-271.

Lowe, D. (1999). Object recognition from local scale-invariant features. University of British Columbia. Vancouver, Canada.

Lord, C. (1995). Follow-up of two-year-olds referred for possible autism. Journal of Child Psychology and Psychiatry, 36, 1365-1382.

Miller, J. (1981). Assessing Language Production In Children. Boston, MA: Allyn \& Bacon.

Nicolosi, L., Harryman, E., \& Kreshek, J. (2004). Terminology of communication disorders speech-language-hearing ( $5^{\text {th }}$ ed.). Baltimore: Williams \& Wilkins.

O’Grady, W. (2005). How children learn language. Cambridge University Press, New York.

Paredis, J, \& Genesee, F. (1996). Syntactic acquisition in bilingual children: Autonomous or interdependent? Studies in Second Language Acquisition, 18, 115.

Paradis, J., Genesee, F., \& Crago, M. (2010). Dual Language Development \& Disorders A Handbook on Bilingualism \& Second Language Learning. $2^{\text {nd }}$ ed. Baltimore, Maryland: Paul H. Brookes Publishing Co., Inc. Print.

Pearson, B., Fernandez, S., Lewedeg, V., \& Oller, D.K. (1997). The relation of input factors to lexical learning by bilingual infants. Applied Psycholinguistics, 18, 4158.

Pearson, B., Fernandez, S.C., \& Oller, D.K. (1993). Lexical development in bilingual 
infants and toddlers: Comparison to monolingual norms. Language Learning, 43, 93-120.

Peters, A. (1977). Language learning strategies. Language 53, 560-73.

Seung, H., Siraj, S., \& Elder, J. (2006). Intervention outcomes of a bilingual child with autism. Journal of Medical Speech-Language Pathology, 14. 53-63.

Scott, K. (2012). Research into children with autism. The Journal of Visualized Experiments. JoVE Publishing.

Shipley, K. G. \& McAfee, J. G. (2009). Assessment in Speech-Language Pathology-A Resource Manual. $4^{\text {th }}$ ed. Clifton Park, NY: Delmar Cengage Learning. Print.

Stone, W. L., Lee, E. B., Ashford, L., Brissie, J., Hepburn, S. L., Coonrod, E. E., \& Weiss, B. H. (1998). Can autism be diagnosed accurately in children under 3 years? Journal of Child Psychology and Psychiatry and Allied Disciplines, 40(2), 219- 226.

Sundara, M., Polka, L., \& Molnar, M. (2008). Development of coronal stop perception: Bilingual infants keep pace with tier monolingual peers. Cognition, 108, 232-242.

Trueswell, J.C. (2004). Using eye movements as a developmental measure within psycholinguistics. Chapter 3, pg. 73-92.

Trueswell, J. C., \& Tanenhaus, M. K. (2005). Approaches to studying world-situated language use: Bridging the language-as-product and language-as-action traditions. Cambridge, Mass.: MIT Press.

U.S. Census Bureau, 2010 American Community Survey.

Volterra, V., \& Taeschner, T. (1978). The acquisition and development of language by bilingual children. Journal of Child Language, 5, 331-326.

Vihman, M., Thierry, G., Lum, J., Keren-Portnoy, T., \& Martin, P., (2007). Onset of word form recognition in English, Welsh, and English-Welsh bilingual infants. Applied Psycholinguistics, 28, 475-493.

Weiss, C., Grodon, M., \& Lillywhite, H. (1987). Clinical Management of Articulatory and Phonological Disorders. $2^{\text {nd }}$ ed. Baltimore, MD: Williams \& Wilkins.

Werker, J., Byers-Heinlein, K., \& Fennel, C. (2009). Bilingual beginnings to learning words. Philosophical Transactions of the Royal Society B, 364, 3649-3663. 
APPENDICES 
APPENDIX A: Receptive One-Word Picture Vocabulary Test

The Receptive One-Word Picture Vocabulary Test (ROWPVT) and the

(ROWPVT-SBE) Spanish-Bilingual Edition, are individually administered, norm-

referenced tests designed for use with individuals ages 2 years 0 months through 18 years

11 months (4 years 0 months through 12 years 11 months- bilingual) (Brownwell, 2000).

Norms are based on a sample of individuals residing in the United States who range from monolingual Spanish speakers with minimal English language skills to individuals who speak mostly English and some Spanish.

An important feature of the ROWPVT is the equivalence of its norms to those of the Expressive One-Word Picture Vocabulary Test (EOWPVT). Because of this equivalence, an individual's score on one test can be accurately compared to a score on the other test. If a difference between the scores is noted, the user of the tests can conclude, with confidence, that a true difference in expressive and receptive vocabulary exists.

The test offers a quick and reliable measure of an individual's bilingual hearing vocabulary, which is assessed by asking the individual to identify an illustration that depicts the meaning of a word presented orally by the examiner.

\section{DESCRIPTION OF THE TEST}

The ROWPVT includes a manual, a set of 170 full-color test plates ordered in respect to difficulty, and a package of record forms. The test plates are contained in a spiral booklet with a flip-out easel for use when presenting the images to the examinee. The entire test can be administered in 10 to 15 minutes and scored in less than 5 minutes. 
Since the test plates are ordered in respect to difficulty, only those items within the individual's range of ability need to be administered.

\section{PURPOSE and USES}

The ROWPVT-SBE provides a measure of an individual's bilingual hearing vocabulary that reflects the extent of that individual's understanding of single words presented. It is a measure that depends on a number of component skills and that has implications regarding an individual's cognitive, language, and academic performance.

On the ROWPVT-SBE, individuals may respond to either Spanish or English stimulus words. The ROWPVT-SBE does not provide a measure of Spanish proficiency or English proficiency. Instead, it assesses acquired receptive vocabulary without regard to whether the vocabulary is in the examinee's first or second language. In contrast to tests of monolingual proficiency, the ROWPVT-SBE permits responses to words presented in either language (minimizing environmental factors related to bilingualism), and therefore, provides an assessment of the total conceptual vocabulary acquired by an individual. This performance is then compared to the performance of bilingual peers.

Listed below are a number of specific uses of the ROWPVT and the ROWPTVTSBE. Those with a more detailed description are those which will be used for the purposes of this study.

Assessing the Extent of Hearing Vocabulary.

The ROWPVT-SBE requires the individual to identify the meaning of words that range from familiar to obscure and in this way provides an 
assessment of how an individual's vocabulary compares to what is expected of bilingual individuals at a particular age level.

Assessing Cognitive Ability.

Because vocabulary acquisition is related to the efficiency with which an individual learns, it can provide a peripheral view of cognitive ability.

Because ability is multifaceted, results used in this way should be viewed with caution, and further assessment should always be conducted to support findings.

Diagnosing Reading Difficulties.

Comparing Bilingual Language Acquisition to Monolingual Language

Proficiency.

Diagnosing Expressive Aphasia.

Screening Preschool and Kindergarten Children.

Assessing Vocabulary with a Nonverbal Response Requirement.

Because the ROWPVT and the ROWPVT-SBE does not require an oral response, they can be administered to individuals who are shy and reluctant to respond verbally, or to individuals who cannot give a verbal response. Even with individuals who have grossly restricted motor controls, the test can be given as long as the individual can give a yes-orno signal.

Evaluating an English Learner's Vocabulary

Monitoring Growth.

Evaluating Program Effectiveness. 


\section{TEST ADMINISTRATION PROCEDURE}

Note: Testing should be conducted in an environment that is free of visual and auditory distractions. In addition, the examinee should be calm and rested. When practical, it is recommended that testing be conducted in the early part of the day since this is the time when individuals are most rested and better able to devote concentration to a task.

1. Determine the examinee's dominant language by answering the questions that appear on the record form. Use this language to deliver the instructions, prompts, and cues to the examinee. You may offer instruction in the non-dominant language whenever this might be helpful to the examinee.

2. Find the suggested starting point based on the examinee's age.

a. Establish chronological age to identify the number at which testing should begin. Chronological age will also be used to identify the appropriate table to use in determining normative scores.

3. Say: "I am going to show you some pictures, and I want you to point to (or identify using the eye-tracker) the picture that is the same as the word I say. If you pick the wrong answer, I'll say the same word in Spanish and you'll have a second chance to pick the right answer."

4. Administration: Administer the example items to all students. Begin with the test plate that corresponds to the examinee's chronological age. Have the examinee attempt examples A through D in the testing booklet (images from the booklet will already be imported to the eye-tracker). Instruct the examinee as needed to understand the task.

5. Establish a basal and ceiling. 
a. BASAL: Establish a basal of 8 consecutive correct responses.

- To establish the basal level of eight consecutive correct responses, begin testing at the point indicated on the record form for the examinee's chronological age. If the examinee does not establish a basal of eight consecutive correct responses, return to the first item administered and work backward until the examinee does establish a basal or until item 1 has been administered. Then continue presenting items in a forward direction, beginning with the item following the item that indicated the necessity of working backward.

b. CEILING: Establish a ceiling of 4 out of 6 consecutive items.

- Continue presenting the test plates in ascending order until the examinee makes six errors out of eight consecutive items or the last item of the test is administered. The ceiling will be the last item of the six consecutive items or the last item on the test if a ceiling is not otherwise reached.

6. Record the number of the examinee's response choice for each item administered.

a. If the examinee misses the item in his or her dominant language, administer the item in the non-dominant language. If the examinee responds by selecting the same picture, prompt the examinee to try again. (If the examinee responds correctly in either language, the item is counted as correct.)

7. If the examinee identifies the correct picture after having been given the item in Spanish circle the "S." If he or she identifies the correct picture after having been given the item in English, circle the "E." 
8. Mark errors with a slash through the scored item number that appears at the end of the line (and before the "S" and "E").

\section{TEST RESULTS INTERPRETATION}

\section{DERIVATION OF NORMS}

Raw scores by themselves, provide little information about an individual's level of performance. Raw scores must be converted to a metric that provides a comparison to a standard.

- RAW SCORES: The examinee's raw score is the number of correct responses up to the last item in the ceiling. All responses below the basal are considered correct. If the examinee establishes two or more ceilings, the lowest ceiling is used to compute the raw score. If the examinee establishes two or more basals, the one closest to the ceiling is used.

\section{STANDARDIZATION}

During the months of January through June 1999, the standardization edition was administered to 3,661 individuals. Testing was conducted at 220 sites in 117 cities in 32 states across the U.S. To use the results from any test, raw scores need to be converted to a metric that provides a comparison to a standard. The most common and useful derived scores are the standard scores, percentile ranks, and age equivalents. These are the types of scores derived from the ROWPVT.

- STANDARD SCORES: Standard scores describe a person's relative standing when performance is compared to a larger normative population. They can be used to compare an individual's performance to other tests that also have derived scores, as long as the norms for each test are based on normal 
distributions having the same mean and standard deviation. Standard scores were derived based on a distribution having a mean of 100 and a standard deviation of 15. Tables for standard scores corresponding to raw scores are provided for ages 2-4 in one-month intervals, for ages 5-10 in two-month intervals, ages 11-13 in three-month intervals, and for ages 14-18 in fourmonth intervals.

- PERCENTILE RANK: The percentile rank corresponds directly to the normal distribution. The same standard score obtained at any age level will always be associated with the same percentile rank.

- AGE EQUIVALENTS: Age equivalents correspond to the median raw scores obtained by individuals within a particular group.

\section{STRENGTHS AND WEAKNESSES}

\section{WEAKNESSES:}

- As a test of English and Spanish-bilingual hearing vocabulary, the ROWPVTSBE samples only a limited number of skills from what we regard as the comprehensive collection of skills that define an individual's ability.

- Results from the ROWPVT-SBE should be used in conjunction with other measures to more fully understand an individual's profile of language abilities.

- The ROWPVT-SBE only tests for receptive language abilities.

- Since performance on this test can be affected by a variety of factors, including hearing problems or visual deficits, poor performance on the test must be interpreted in light of other findings. 
- Many factors may affect the particular score a child receives that are unrelated to language ability. With administration of a standardized test such as the ROWPVT-SBE, these must be taken into account to allow for individualization.

- Tests don't diagnose.

- Diagnosis and hypotheses based on test results must be confirmed by other observations of the child.

\section{STRENGTHS:}

- The ROWPVT-SBE assesses hearing vocabulary in English and Spanish-bilingual individuals and can provide important information about an individual's level of receptive language functioning.

- While a comprehensive evaluation of language skills requires more than an examination of the individual's ability to comprehend single words, administration of the ROWPVT-SBE provides a practical, objective, and efficient step in this process.

- The ROWPVT-SBE is a simple and time efficient test to administer and score.

- Results are norm-referenced; so individual scores can be compared to a larger group of similar individuals.

- Knowledge of the child's receptive language skills can aid the clinician in developing intervention goals and activities.

\section{RELIABILITY AND VALIDITY}

\section{Reliability}


The ROWPVT-SBE provides a consistent measure that is relatively free of error. The test is comprised of content that has a high level of homogeneity and provides consistent measurement from one testing to the next, and can be scored consistently by different examiners. This high level of reliability was observed across all ages for which the test is intended. Based on these findings, users of the test can have a high degree of confidence in the tests results.

Internal Consistency:

To assess internal consistency of test items Cronbach's coefficient alpha was computed at each age level. This statistic yields the estimate of the uniformity of the test items based on their intercorrelations. Another measure is split-half coefficient, which is the correlation between the scores derived from the odd numbered items with scores from even-numbered items. High correlations from each of these analyses indicate internal consistency of the test items and provide an index of the amount of error associated with the test results. Coefficient alpha and split-half reliability coefficients were computed by age group for all individuals participating in the standardization study. In table 7.1 (coefficients) are relatively high for all age groups. Coefficient alphas range from .95 to .98 with a median of .96; split half coefficients, corrected for the full length of the test, range from .97 to .99 with a median of .98 .

Temporal Stability:

Test-retest reliability provides evidence of the stability with which a test assesses the same individual over time. The test was given to 226 examinees and each were retested by the same examiner. The average duration between the first and the second testing was 20 days. The corrected test-retest correlations range from .78 to .93 with a 
coefficient of .84 for the entire sample. The test-retest coefficients provide evidence that the use of the ROWPVT is sufficiently stable over time, in terms of the relative ranking of individuals from one testing to the next. Gain scores range from a standard score gain of 2.12 to 4.65 , with an average standard score gain of 3.05 for the entire sample. Interrater Reliability:

Interrater reliability refers to the consistency with which different examiners are able to obtain the same rating of an examinee's ability. For the ROWPVT, interrater reliability was evaluated by examining the consistency with which examiners are able to follow the scoring procedure after the test has been administered. To conduct this study, 30 protocols were randomly selected from the standardization sample, two from each of the 15 age levels. Each protocol was administered by a different examiner. The protocols showed items marked right or wrong but did not show an indication of a basal, ceiling, or raw score. Two trained and two untrained scorers of this exam were asked to score the test following the manual instructions. Results were than compared to computer scoring of the protocols. The results of this analysis showed 100 percent agreement between all of the scorers. This finding suggests that the method of scoring and the scoring instructions are sufficiently clear so that scoring can be carried out consistently.

\section{Validity}

\section{Content Validity:}

For the ROWPVT-SBE, a format for the test was selected in which an examinee could demonstrate his/her understanding of single English words by identifying illustrations that depict the meanings of words of progressive difficulty. Items were 
selected from a variety of sources to represent words that individuals at a given age level, regardless of their gender or cultural background, could be expected to have an equal likelihood of knowing. Only words with meanings that could be depicted in illustrations were selected.

\section{Criterion-Related Validity:}

Criterion-related validity shows how closely one set of scores is correlated with scores from other tests that directly and independently assess the same ability. Concurrent validity is a type of criterion-related validity that is evaluated by correlating sets of scores from one test, such as the ROWPVT-SBE, with scores from another similar test taken by the same group at the same time or within a reasonably close time period. If the scores are highly correlated, it can be assumed that both tests tap the same skill. Table 8.1 shows the correlations between the ROWPVT-SBE and several other vocabulary tests. The majority of the receptive vocabulary tests ask the examinee to identify a picture that matches a word presented by the examiner from several alternatives. The corrected correlations between the ROWPVT and these tests range from .44 to .97 with a median of .71. The median correlation with the receptive tests is .63 . These correlations indicate that the ROWPVT-SBE is measuring a similar behavior as the criterion tests.

\section{Construct Validity:}

The evaluation of construct validity requires information from a variety of sources. Data is provided to address each of the following assumptions:

Chronological Age- Individuals vocabulary increases as the individual matures. Test scores should show a positive relationship. 
Cognitive Ability- The relationship between vocabulary and cognitive ability is well documented. Test scores should show a positive relationship. Language- Vocabulary is one aspect of the total complex of language skills, and these skills are interrelated. Test scores should show a positive relationship. Academic Achievement- Vocabulary and academic achievement are related. Test scores should show a positive relationship.

Receptive and Expressive Vocabulary- Measures of receptive and expressive vocabulary, while related, tap a unique process. While a positive relationship should show, unique variance should be present.

Previous Editions- The current edition of the ROWPVT-SBE is expected to measure the same construct as previous editions of the test. A strong positive relationship should exist between the tests.

Exceptional Group Differences- Because individuals who typically have academic difficulties are likely to show vocabulary deficits, the results for the test should be lower for students having related disabilities. 
APPENDIX B: IRB Form

\section{Language Comprehension in Children with Autism}

\section{RESEARCH OBJECTIVES:}

Autism and Autism Spectrum Disorders (ASD) are disorders of neural development characterized, in varying degrees, by difficulties in social interaction, verbal and non verbal communication and repetitive behavior. Although autism appears to have its roots in very early brain development, the most obvious signs of autism and symptoms of autism tend to emerge between 2 and 3 years of age. According to the U.S. Center for Disease Control and Prevention (CDC) 1 in 88 American children (1 in 54 boys and 1 in 252 girls) are on the autism spectrum, a ten-fold increase in prevalence in 40 years. Moreover, autism statistics show that prevalence rates have increased 10 to 17 percent annually in recent years, affecting over 2 million individuals in the U.S.

In terms of language development, children with autism tend to be delayed in typical language development milestones, such as babbling and speaking. Children with autism may also present difficulties in combining words in meaningful sentences, may speak only single words or repeat the same phrase over and over. They may also go through a stage in which they repeat what they hear (echolalia).

Language abilities in children with autism are generally assessed using vocabulary tests like the Receptive One-word Picture Vocabulary Test. Nevertheless, these tests require an interaction between the Speech Language Pathologist and the client because the child is expected to point to pictures. For example, the child is shown pictures of a tree, a boy, a man and a tie and upon listening to a sentence like "Which picture shows a man?", the child is supposed to point to the picture depicting a man. Given the social interaction problems characteristic of children with autism and in the ASD, it could be the case that the language capacities of these children are not completely assessed because they are required to interact and point to pictures.

This research project aims to study language comprehension abilities in children with autism using eye-tracker technique. Eye-tracker captures and records children's eye movements and could help in the assessment of language abilities in children with autism because it does not require any interaction or pointing. Thus, eye-tracker could give a more accurate measure of children's language comprehension abilities. Monolingual English and bilingual (Spanish-English) children with Autism and in the ASD would be tested. We expect that their language comprehension abilities would be better when tested with eye-tracker than when tested traditionally.

\section{SUBJECT RECRUITMENT:}


This research involves 300 children with Autism and in the ASD from monolingual English and bilingual Spanish/English homes living in the Miami, Florida area, age 4 to 7 , whose parents would give permission to participate in this research program. An effort will be made to include equal numbers of males and females in each experiment. Children from all backgrounds will be recruited. Given the demographics of the Miami area $(66 \%$ Hispanic and $34 \%$ non-Hispanic with racial breakdown of .2\% American Indian, . $7 \%$ Asian, .04\%Hawaiian, $22 \%$ Black, $67 \%$ White, $5 \%$ more than one race, and $5 \%$ unreported), with a large Hispanic population (66\%), we do not anticipate problems to recruit monolingual English and bilingual Spanish/English children.

Children will be recruited by posting ads, contacting speech language therapy centers and centers specialized in the treatment and education of children with autism and in the ASD. Parents will be explained the project and will be asked whether they want to participate in the project.

The children should be from monolingual English and bilingual Spanish/English homes, be the relevant age for the study, and be diagnosed with autism or in the ASD. No other inclusion restriction applies.

\section{METHOD AND PROCEDURES:}

The procedures involve coming to the Psycholinguistics Laboratory for approximately one hour on two separate occasions (if the child is bilingual) and on one occasion (if the child is monolingual). On the first occasion, children will be tested using a standardized test (ROWPVT- Receptive One Word Picture Vocabulary) that is used to measure language comprehension abilities in children with autism. The results of this test will be later compared to the eye-tracker results. Then children will participate in the eye-tracker experiment. They will be tested in English or Spanish (if they are bilingual) and in English (if they are monolingual). In the second occasion they will be tested in the language they haven't been tested yet (English or Spanish). Children participating in this research are in the presence of the caregiver throughout the whole experiment. There are no apparent physical, psychological, social, or legal risks or discomfort for subjects in this research. The eye-tracker stimuli are picture images and recorded speech, neither of which is known to be harmful to children. These stimuli have been used in numerous experiments of language comprehension without negative side effects. Children participating in these studies occasionally experience some mild stress, which normally surfaces in the form of fussiness or distraction. Experimenters will be trained to notice any sign of discomfort on the part of the children, and to discontinue their participation in the experiment when these signs of discomfort become apparent. Also, all caregivers will be informed of the right to terminate their children's participation in the experiment without any penalty.

The research will be conducted at the Psycholinguistics Laboratory in the Communication Sciences and Disorders department, AHC3 building. 
The study will start on May 21 ${ }^{\text {st }}, 2012$ and will finish on May $21^{\text {st }}, 2016$.

The materials used in this research consist entirely of behavioral data, recorded by an eye tracker device for specific use in this research. Behavioral data will be collected by recording children's gaze to images presented in the eye-tracker computer screen. All information collected in the study is confidential and the subject's name will not be identified at any time. Codes linking study ID numbers and participants names will be kept in a separate locked cabinet. Reported data refer to subjects' means, collapsed over individual subject data. On rare occasions where individual subject data may be of interest, such data will be reported by referring exclusively to subject's study ID number. Only the Principal Investigator and the research assistants will have access to individually identifiable private information about the subjects.

\section{BENEFITS:}

There is no expected risk to subjects with this research. The investigation of language comprehension abilities in monolingual and bilingual children with autism will contribute to research in language development and autism, communication sciences and disorders, developmental psychology, and linguistics. In this sense, this research has potential benefits to the participants and the society in general given that it can shed light on topics of autism research, particularly language development. Although participants will be informed that the experiment is not designed to help their child or him/her personally, they may benefit as well since data from standardized tests and eye-tracker will be compared in order to have a better understanding of the child's language comprehension abilities. Before the experiment, parents will receive a brief explanation of the research question, the hypotheses tested, and will be informed that the investigator hopes to learn more about language comprehension and development in children with autism.

\section{RISKS TO SUBJECTS:}

There are no apparent physical, psychological, legal, or behavioral risks associated with the project. The only minor risk is that children occasionally experience some mild stress, which normally surfaces in the form of fussiness or distraction. To minimize this risk, the experimenter will (a) be trained to notice any sign of discomfort on the part of the children or their caregivers; (b) allow parents to terminate the experimental session at any time; (c) encourage parents manifesting any discomfort to terminate the experiment and praise the child and parent for their effort. There is no risk to subjects' confidentiality. We will protect confidentiality by never associating any personally identifying labels to any data.

\section{INFORMED CONSENT:}

Each parent will be provided with a written consent form, informing that (a) participation in the research is voluntary, and may be terminated at any time without any penalty; (b) explaining the purpose of the research, the procedure, and its expected benefits; (c) 
declaring that the research carries no anticipated discomfort or risk; (d) assuring the confidentiality of the results. This form will be signed by the parent and the experimenter prior to the experiment. In addition, parents will be verbally informed of all procedures, their right to terminate their participation at any time, and to contact the PI for any questions during or after the research. Children will participate in a study only if their parents have read the instructions and have being invited to ask questions.

A parental/guardian consent form will be used.

\section{CONFIDENTIALITY OF DATA:}

All information collected in the study is confidential and the subject's name will not be identified at any time. Codes linking study ID numbers and participants names will be kept in a separate locked cabinet. Reported data refer to subjects' means, collapsed over individual subject data. The final analyzed results will be published in group format. On rare occasions where individual subject data may be of interest, such data will be reported by referring exclusively to subject's study ID number. Only the Principal Investigator and the research assistants will have access to individually identifiable private information about the subjects. 
APPENDIX C: FIU Informed Consent Form

\section{PARENTAL CONSENT TO PARTICIPATE IN A RESEARCH STUDY}

\section{Title: Language Comprehension in Children with Autism}

Your child is being asked to participate in a research study conducted by Professor Ana Gouvea of the Communication Sciences and Disorders Department at Florida International University. The study will include about 300 children with autism, age 4 to7, whose parents would give permission to participate in this research program.

The purpose of this research is to study language comprehension abilities in monolingual and bilingual (English/Spanish) children with autism.

The procedures involve coming to the Psycholinguistics Laboratory for approximately one hour on two separate occasions (if the child is bilingual) and on one occasion (if the child is monolingual). Your child will seat in front of a computer monitor specially designed to track eye movements when stimuli (e.g. pictures) are presented in the computer screen. Your child will be presented with some pictures in the computer screen followed by an orally presented sentence or word that matches one of the pictures. The child's eye movements will be recorded in order to determine where the child looks at when presented with the oral stimuli. You will be with your child throughout the whole experiment.

There are no apparent physical, psychological, social, or economic risks or discomfort for your child in this research. Your child might experience some mild stress, which normally surfaces in the form of fussiness or distraction. The experimenters are trained to notice any sign of discomfort on the part of your child or yourself, and to discontinue your child's participation in the experiment when these signs of discomfort become apparent.

These experiments are not designed to help you or your child personally, but the investigator hopes to learn more about language development in children with autism. You are free to ask questions or to withdraw your child's participation at any time without penalty. There is no cost or payment to you or your child as a subject.

The records of this study will be kept private and will be protected to the fullest extent provided by law. In any sort of report we might publish, we will not include any information that will make it possible to identify your child as a subject. Research records will be stored securely and only the researcher team will have access to the records. However, your child's records may be reviewed for audit purposes by authorized University or other agents who will be bound by the same provisions of confidentiality. 
If you would like more information about this research after you are done, you can contact Dr. Ana Gouvea at (305) 348-0362 or by email at agouvea@fiu.edu. If you would like to talk with someone about your child's rights of being a subject in this research study or about ethical issues with this research study, you may contact the FIU Office of Research Integrity by phone at 305-348-2494 or by email at ori@fiu.edu.

I have read the information in this consent form and agree to allow my child to participate in this study. I have had a chance to ask any questions I have about this study, and they have been answered for me. I understand that I am entitled to a copy of this form after it has been read and signed.

Signature of Parent/Guardian

Date

Printed Name of Parent/Guardian

Printed Name of Child Participant 


\section{APPENDIX D: Advertisements for Research Participation}

\section{About the Language Development Lab}

The Language Development Lab at the Communication Sciences and Disorders department at FIU conducts research on language development and is currently looking for 4 to 7 year old, monolingual and bilingual children with autism to participate in their research. The research uses state -of-the-art technology with the aim of determining a child's language abilities.

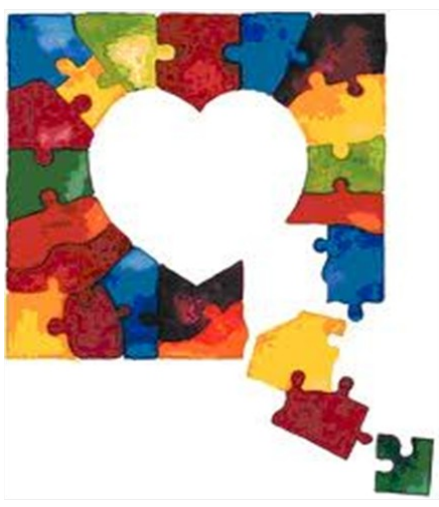

How much language does your child understand?

We would like to invite you and your child to participate in one of our studies at the Language Development $\mathrm{Lab}$ at the Communication Sciences and Disorders Department at FIU. We are currently testing 4 to 7 year old, monolingual and bilingual children with autism.

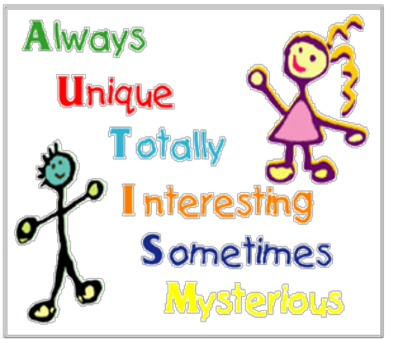

\begin{abstract}
About the lab director Dr. Ana Gouvea, Ph.D

Dr. Gouvea is an Assistant Professor in the Communication Sciences and Disorders Department and the Director of the Infant Language Development Laboratory at Florida International University. Her research on how monolingual and bilingual toddlers learn monolingual and bilingual toddlers learn
language is currently funded by the National Institute of Health
\end{abstract}

Dr. Gouvea did her Ph.D. in the Linguistic department at the University of Maryland. She studied how people comprehend sentences using different techniques, including Electroencephalography (EEG). After her Ph.D., she worked as a postdoctoral researcher at the University of California, San Francisco (UCSF) and at the Infant Cognition Laboratory at San Francisco State University (SFSU) where she did research on language development with infants.

Language Development Lab

Florida International University

Department of Communication Sciences and

Disorders

11200 SW 8 Street

AHC-3

Miami, FL 33199

Email: babytalk@fiu.edu

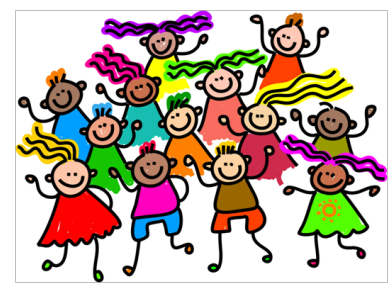

What we do:

The lab is interested in studying language abilities in children with autism using the eye-tracker technique.

The eye tracker is a state-of-the-art device that measures eye movements without requiring any interaction with the experimenter. If your child is presented a picture and a word related to it, we would be able to track the movement of the child's eyes to determine whether or not the child comprehends the word. This is a useful technique to test language abilities in typically developing children as well as children with autism.

The procedure we use is simple, brief and entirely safe. All information we collect during these visits remains entirely confidential.

\section{Children with Autism:}

How much

language do they really know?

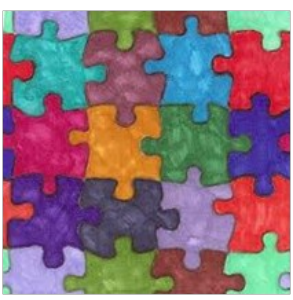

Language Development Lab

Florida International University
Department of Communication Department of Communication Sciences and Disorders
Interested in Participating?

- Appointments are available to suit your schedule.

- The entire visit takes about one hour.

- Please feel free to call us or send us an email if you are interested in participating in our studies or if you have any questions.

- Contact the Language Development Lab at (305)348-4765 or via email at babytalk@fiu.edu. 


\section{How much vocabulary does your child understand?

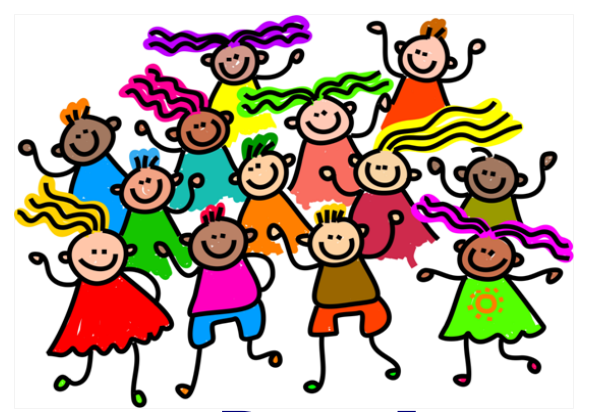 \\ Language Development Lab}

We would like to invite you and your child to participate in one of our studies:

- We are currently testing 4 to 7 year old children with autism.

- Your child's receptive vocabulary will be tested in an entirely safe procedure.

- Your child will remain with you at all times.

For more information or to schedule a visit, please contact us:

\section{Department of Communication Sciences \& Disorders}

Florida International University

I 200 SW 8 Street • AHC-3 • Miami, FL 33199

305-348-4765

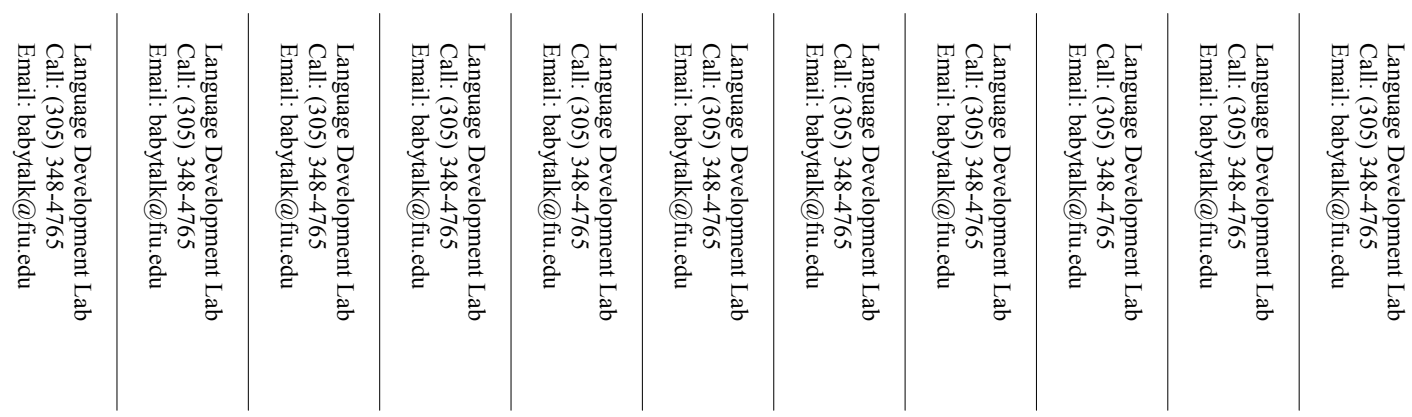




\section{Dear Parent,}

APPENDIX E: Parent Letters for Research Participation

An open question in autism research is how much language a child with autism knows and how to assess language abilities in this population.

We are contacting you to ask for your help in furthering this exciting and important research. At the Psycholinguistics Laboratory at Florida International University, we study language development in children with autism and in the ASD. We would like to invite you to bring your child to our lab and participate in our research, or have your child participate in our research at their school or therapy center at your convenience.

Our research investigates vocabulary development in monolingual and bilingual children with autism. The procedure we use is simple, brief and entirely safe. The procedure involves coming to the Psycholinguistics Laboratory for approximately one hour. Your child will sit in front of a computer monitor specially designed to track eye movements when stimuli (e.g. pictures) are presented on the screen. Your child will be presented with pictures on the computer screen followed by an orally presented sentence or word that matches one of the pictures. The child's eye movements will be recorded in order to determine which picture the child looks at when presented with the oral stimuli. After that, your child will be tested using a standardized, paper and pencil test (ROWPVT- Receptive One Word Picture Vocabulary Test) that is used to measure language comprehension abilities in children with autism. In this test, they will be presented with the same pictures seen on the computer screen, except this time, they will be asked to point to a picture when the oral stimuli is presented.

The results of the ROWPVT test will be later compared to the eye-tracker results. Eye-tracker captures and records children's eye movements and could help in the assessment of language abilities in children with autism because it does not require any interaction or pointing. Thus, the eye-tracker could yield a more accurate measure of children's language comprehension abilities.

We are interested in testing monolingual (English or Spanish), or bilingual (English and Spanish) children ages 4 to 8 years old.

If you are interested in participating in our study, please contact us by phone at (305) 348-4765 or by email at babytalk@fiu.edu. An appointment can be made to suit your schedule. Come and visit our lab, contribute to our research and learn more about your child's development! Thank you very much for your consideration. We look forward to hearing from you soon.

Best, Ana C. Gouvea, Ph.D.

Assistant Professor and Director, Language Development Laboratory

Department of Communication Sciences and Disorders

College of Nursing and Health Sciences

Florida International University 
Dear Hawkes Bluff Parent,

My name is Melissa Pierro and I am a graduate student at Florida International University and former volunteer/ intern at Hawkes Bluff under the supervision of Speech Language Pathologist Maria Marina. I am currently working on my master's thesis project to complete my degree in Speech Pathology this May, and would greatly appreciate your help. I am conducting research on language development in children with autism and in the autism spectrum. I am contacting you because the speech pathology department at Hawkes Bluff thought your son/daughter would be a great candidate. I am interested in testing monolingual or bilingual (English and Spanish) children ages 4 to 10 .

I will be conducting the study at Hawkes Bluff Elementary under the supervision of speech pathologist Maria Marina. If your child is receiving speech and/or language services, the research can be conducted during their normal therapy session. If not, they will be pulled from class for no more than 30 minutes. The procedure is very simple. Your child will sit in front of a computer monitor specially designed to track eye movements when pictures are presented on the screen. Your child will be presented with 4 pictures followed by an orally presented sentence that matches one of the pictures. His or her eye movements will be recorded in order to determine which picture he/she looks at when presented with the oral stimuli. After that, he/she will be tested using a standardized paper and pencil test (ROWPVT- Receptive One Word Picture Vocabulary Test) that is used to measure language comprehension abilities in children with autism. In this test they will be presented with the same pictures seen on the computer screen, except this time, they will be asked to point to the picture when the oral stimuli is presented. The results of the ROWPVT test will be later compared to the eye-tracker results. These scores will be available to you upon request. Eye-tracker captures and records children's eye movements and could help in the assessment of language abilities in children with autism because it does not require any interaction or pointing. Thus, the eye-tracker could yield a more accurate measure of children's language comprehension abilities.

Attached you will find a letter from my professor, Dr. Ana C. Gouvea, a flyer containing more information about the study, and a consent form. In order for your child to participate, please sign and return the consent form to your child's teacher. I would greatly appreciate your help and support in this important research. The results using this latest technology, will ultimately enable us to create more advanced therapy methods for autistic children. Please feel free to contact me with any questions you may have at 954558-8034 or mpierro20@aol.com. Thank you! -Melissa Pierro 
APPENDIX F: Bilingualism Parent Questionnaire

Bilingual Questionnaire

\begin{tabular}{|l||}
\hline \multicolumn{1}{|c||}{ Office Use } \\
Spanish Subject \# \\
English Subject \# \\
Lang. Dominance: \\
\hline SES:
\end{tabular}

\section{Child's Basic Information}

Child's Gender:

Child's Date of Birth Today's Date

Child's Age : Country you/your family are from:

Was the child premature? If so, how many weeks?

Child's Diagnosis:

Severity: Mild/ Moderate or Severe?

Verbal or Non-Verbal:

Date of child's last evaluation: Measure:

Do you know how many words your child produces verbally?

Do you know how many words your child comprehends?

\section{Parents' Information}

1. What are the native languages of the parents? Mother: Father:

2. Do the parents speak any other language(s)? If so at what age was it learned? 
3. What is the highest level of education completed by the parents? Mother: Father:

4. Language of instruction in the highest degree: Mother: Father:

5. What are the occupations of the parents? Mother:

Father:

\section{Child's Language Environment}

What language(s) do the parents speak to the child? Mother:

Father

Who is the primary caretaker (the person that spends the majority of the day with the child)? What language(s) does this person speak to the child?

How many hours a day does the child spend awake with the primary caretaker?

Who is the secondary caretaker (the other person regularly in charge of the child, such as a babysitter or grandparent)? What language(s) does this person speak to the child?

How many hours a day does the child spend awake with the secondary caretaker?

How many people are in the household altogether?

With who does the child spend the weekends? During this time, how many languages is the child exposed to? How many hours? 
What language(s) do each of these other people speak to the child? Approximately how much time do each of these people spend with the child per day?

Does the child go to a day-care center? If yes, how much time does the child spend there per week and what language(s) is spoken to the child?

Is the child exposed to any other language? What language? How much time per day or week is the child exposed to this language?

What language does the child speak more often?

\% English

$\%$ Spanish

In your opinion what is the child's dominant language (i.e., the language that the child speaks or understands the best? 


\section{Your Child's Weekly Language Schedule}

Please fill out your child's approximate weekly schedule.

\begin{tabular}{|c|l|}
\hline & If the child is sleeping at that time, leave the hour block blank. \\
\cline { 1 - 2 } S & If the hour is primarily in Spanish, write an S in the square. \\
\cline { 1 - 1 } $\mathrm{E}$ & If the hour is primarily in English put an E. \\
\cline { 1 - 1 } $\mathrm{O}$ & If the hour is in a language besides English or Spanish put an O. \\
\hline
\end{tabular}

\begin{tabular}{|c|c|c|c|c|c|c|c|c|}
\hline & Sunday & Monday & Tuesday & Wed. & Thursday & Friday & Saturday & \\
\hline $12: 00$ AM & & & & & & & & $12: 00 \mathrm{AM}$ \\
\hline 1:00 AM & & & & & & & & 1:00 AM \\
\hline 2:00 AM & & & & & & & & 2:00 AM \\
\hline 3:00 AM & & & & & & & & $3: 00 \mathrm{AM}$ \\
\hline 4:00 AM & & & & & & & & 4:00 AM \\
\hline 5:00 AM & & & & & & & & 5:00 AM \\
\hline 6:00 AM & & & & & & & & 6:00 AM \\
\hline 7:00 AM & & & & & & & & 7:00 AM \\
\hline 8:00 AM & & & & & & & & 8:00 AM \\
\hline 9:00 AM & & & & & & & & 9:00 AM \\
\hline 10:00 AM & & & & & & & & 10:00 AM \\
\hline 11:00 AM & & & & & & & & $11: 00$ AM \\
\hline 12:00 PM & & & & & & & & 12:00 PM \\
\hline 1:00 PM & & & & & & & & 1:00 PM \\
\hline 2:00 PM & & & & & & & & 2:00 PM \\
\hline 3:00 PM & & & & & & & & 3:00 PM \\
\hline 4:00 PM & & & & & & & & 4:00 PM \\
\hline 5:00 PM & & & & & & & & 5:00 PM \\
\hline 6:00 PM & & & & & & & & 6:00 PM \\
\hline 7:00 PM & & & & & & & & 7:00 PM \\
\hline 8:00 PM & & & & & & & & 8:00 PM \\
\hline 9:00 PM & & & & & & & & 9:00 PM \\
\hline 10:00 PM & & & & & & & & 10:00 PM \\
\hline 11:00 PM & & & & & & & & 11:00 PM \\
\hline
\end{tabular}

For office use only:

Hours per week awake:

Hours per week in Spanish:

Hours per week in English:
Dominance percentage:

Dominant language: 
